\title{
Advanced Personal Comfort System (APCS) for the workplace: A review and case study
}

\author{
Sally Shahzad ${ }^{\mathrm{a}}$, John Kaiser Calautit ${ }^{\mathrm{b}}$, Katrina Calautit ${ }^{\mathrm{b}}$, Ben Hughes ${ }^{\mathrm{c}}$, Angelo I. \\ Aquino $^{\mathrm{C}}$ \\ ${ }^{a}$ School of Engineering and Technology, University of Derby, Derby, DE22 3AW, UK \\ ${ }^{b}$ Department of Architecture and Built Environment, University of Nottingham, NG7 2RD, UK \\ ${ }^{c}$ Department of Mechanical Engineering, University of Sheffield, S10 2TN, UK \\ ${ }^{1}$ corresponding author email: sally.shahzad@gmail.com
}

\begin{abstract}
The aim of this research is to investigate the application and performance of an advanced personal comfort system, a thermal chair, using Computational Fluid Dynamics (CFD), Building Energy Simulation (BES) and field test analysis. The thermal chair permits individual control over their immediate thermal environment without affecting the thermal environment and comfort of other occupants. A comprehensive review on the existing research on the design and performance of various personalised thermal control systems was carried out. A prototype of a thermal chair was designed for the study and tested in an open plan office during the heating season in Leeds, UK. 45 individuals used the chair in their everyday context of work and a survey questionnaire was applied to record their views of the thermal environment before and after using the chair. The performance of the chair was investigated through CFD simulations (ANSYS Fluent) providing a detailed analysis of the thermal distribution around a thermal chair with a manikin. Furthermore, a model of a three-story office building with thermal chairs were created and simulated in the commercial BES software, IES Virtual Environment. The benchmark model of the building was validated with previous work and good agreement was observed. The results showed that user thermal comfort can be enhanced by improving the local thermal comfort of the occupant. The additional plug-load energy from the thermal chair was significantly less as compared to the heating energy saved by adjusting the heating set point by $2^{\circ} \mathrm{C}$ during the heating season. Monthly heating energy demand was reduced by $27 \%$ on January and $25.4 \%$ on February. Furthermore, the results of the field study revealed $20 \%$ higher comfort and $35 \%$ higher satisfaction level, due to the use of thermal chair.
\end{abstract}

Keywords: Thermal chair; comfort; open plan office; thermal control; Computational Fluid Dynamics (CFD) 


\section{Introduction}

Currently in the workplace there is a challenge in providing a balance between reducing the building energy performance and improving user comfort. The trend of building energy efficient design has been ongoing for several decades and recently reinforced by increasing awareness of climate change and other environmental challenges by different stake holders in the field such as policy makers, developers, engineers, users, architects and researchers. The building sector currently account for up to $40 \%$ of primary energy consumption in many countries and are a significant source of greenhouse emissions [1,2]. About $50 \%$ of this is for providing heating, ventilation and air-conditioning (HVAC) $[3,4]$. According to the latest reports of the International Energy Agency (IEA), the floor area of commercial and institutional building is expected to double by 2050 and therefore reducing the building energy consumption in these sectors must be a priority [4]. In addition, despite of the substantial energy used to provide comfort and high satisfaction in the thermal environment, poor thermal comfort is one of the most common building users' complaints [5].

Many studies fall in the extreme of the two, in the sense that they are either energy efficient or provide high levels of comfort for the user. Either of these creates difficulties for the other end [6, 7]. Advanced Personal Comfort System (APCS) is a measure mainly to improve occupant thermal comfort and studies found its potential to reduce the overall energy performance of the building. Nevertheless, thermal control in an open plan office is challenging, due to individual differences in perceiving the thermal environment. Personal decisions to adjust the room temperature or ventilation in the office, such as to open a window or to change the settings of the thermostat, directly impacts the comfort of other occupants, who may not share the same preferences. In an attempt to simplify matters, management prefer to replace personal thermal control in the open plan office with centrally controlled thermal systems [8]. However, this decision simply adds on to the complexity of occupant comfort, as the importance of 'to be in control and not to be at the mercy of external forces' is ignored [9]. Providing user control for the thermal environment is the main key factor in occupant thermal comfort [6]. User control directly impacts their acceptance of the thermal environment [10]. Kroner (2006) and Melikov (2004) and (2006) report improved comfort conditions through the application of user thermal control [11-13].

Zhang et al. (2015) use the term 'personal comfort system (PCS) to refer to systems that locally condition the occupant independent of the HVAC system'. They distinguish different personal control systems over the thermal environment. The whole body experience is provided through controlling the temperature of the microenvironment, which is usually not a uniform thermal environment. A 
more localised thermal comfort can be achieved through thermal changes of the body parts. The latter includes feet, face, hands, soles, check, and fingers. Each body segment reacts differently to localised cooling and heating [14]. An 'overshoot' of pleasure for the respondents was reported in body part temperature changes [15-18]. 'In its thermal embodiment, when a less-than-comfortable warm or cold body received a thermal stimulus in the desirable direction, it could produce an observed overshoot of pleasure that exceeds that of a neutral condition' [15-18]. However, limited studies focus on the body part thermal comfort [14]. By reducing the room temperature and the application of personal comfort system, studies showed over 30\% energy saving while achieving much greater user satisfaction [14]. The psychological impact of providing personal thermal comfort has been reported as the main cause of the increased comfort and satisfaction [18].

In this paper, a review of the personalise thermal control systems and a relevant study on an Advanced Personal Comfort System (APCS) in an open plan workplace are included. The review section presents a comprehensive review on the existing research on the design and performance of personalised thermal control systems, including temperature and ventilation controls. The general approach and research in the field are classified and different types of personal control systems are identified and compared regarding the advantages and disadvantages of each system. The performance of these personalised control systems is further analyse using simulations providing a comprehensive analysis of the airflow and thermal distribution. Many of the existing research is carried out in climatic chambers and only a few tested in the field. This study conducted a comprehensive field experiment and survey in a context of every day office environment to assess the effectiveness of the thermal chair in providing comfort. The study section investigates the application of an advanced thermal control system in an open plan setting that allowed users to set their immediate thermal environment according to their requirements. and remain comfortable over a wider range of ambient temperatures. Previous works [14] have shown that allowing the indoor ambient temperature to be lowered by a few degrees can result in large energy savings because the space is heated less intensely and less often.

The work will utilise Computational Fluid Dynamic (CFD), Building Energy Simulation (BES) and field testing to assess the thermal comfort and energy performance of a thermal chair which allows users to control heating that is provided directly through the surfaces of seat and backrest. Initially, CFD analysis will be used to simulate the thermal distribution around a manikin seated on the thermal chair. The commercial CFD code ANSY Fluent will be used. Thermal comfort levels will be calculated using the ASHRAE PMV method. The CFD results will inform the design, construction and field testing of a prototype and optimise performance. 
The model of the office building and the thermal chair will be created in the commercial BES software, IES Virtual Environment. The three-story office building used for the analysis is a narrow open plan office building. The benchmark model will be validated using previous work's data. Three cases will be simulated; normal office chair with the zone thermostat set point kept at $22^{\circ} \mathrm{C}$ (base case), normal office chair with the zone thermostat set point adjusted to $20 \circ \mathrm{C}$ and thermal chair with the zone thermostat set point adjusted to $20^{\circ} \mathrm{C}$. The aim of the field test is to evaluate the effectiveness of the thermal chair at providing comfort in a realistic office environment. For this purpose, a thermal chair prototype equipped with thermal control over the seat and the back will be produced and examined in an open plan office in Leeds, UK during the heating season. The field study will examine the comfort and satisfaction of the users before and after the use of the thermal chair.

\section{Literature Review}

This section will review the performance of four different types of personalised comfort system (PCS) including air terminal device (ATD), task/ambient air conditioning (TAC) System, personalised ventilation chair and cool chair. The review will investigate the capabilities of existing systems to reduce the overall energy demand of buildings, maintain comfort in a wide range of ambient temperatures in an office environment during summer and cold weather conditions and potential to improve air quality (ventilation chair). The review will summarise the advantages and limitations of each system.

\subsection{Air Terminal Device (ATD)}

Air terminal devices (ATD) or "ductless" personalised ventilation ("ductless" PV), integrated with displacement ventilation (DV), are devices which provides clean and treated air to the breathing zone of the users. Halvon 'ova' and Arsen [20] investigated the temperature and quality of the air supplied by an ATD of a ductless personalised ventilation (PV) positioned at a height of $0.2 \mathrm{~m}$ above the floor, as shown in Figure 1. The experimental study allowed test subjects to control the flow rate, i.e. air velocity, flow direction. The study observed that positioning the ductless PV differently did not have any significant impact on the temperature and freshness of the air supplied by the (ATD). Furthermore, the study also recommended different fan speeds for different ambient air temperatures. 


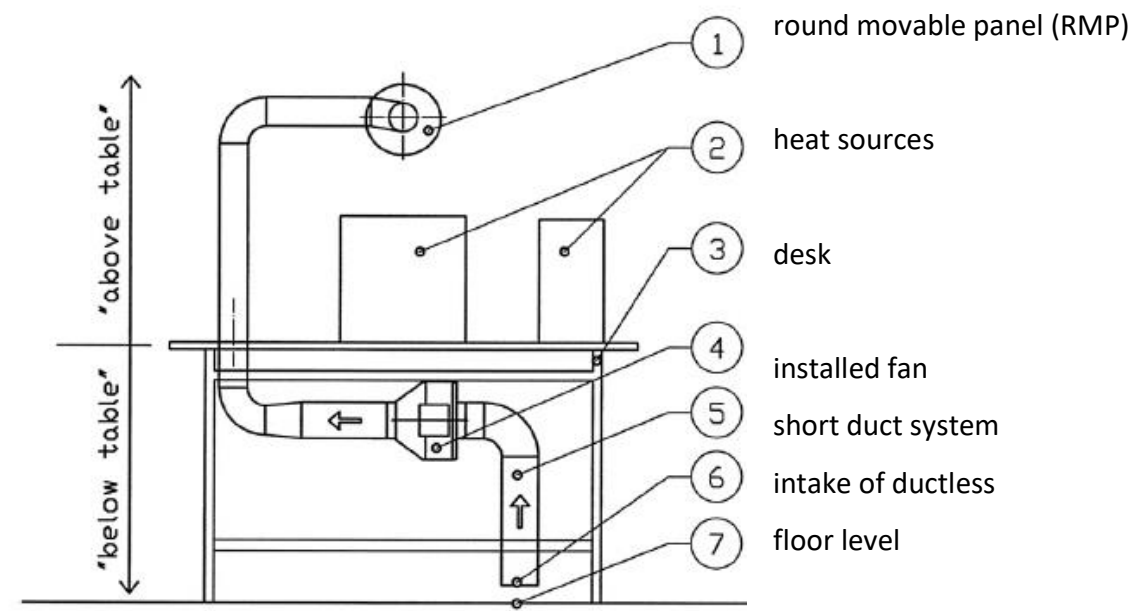

Fig 1. Schematic of a ductless personalised ventilation system investigated by [20].

While Melikov et al. [21] examined the performance of five different types of air terminal device for personalised ventilation/cooling. Prototypes were built, tested, and compared to assess the quality of inhaled air and thermal comfort in a climate chamber. The design and set up of different air terminal devices (ATD) including computer monitor panel (CMP), moveable panel (MP) vertical desk grill (VDG), personal environments module (PEM), and horizontal desk grill (VDG) are shown in Figure 2a. The experiments were conducted in Denmark during summer and winter conditions. The work focused on comparing the reduction in the whole-body equivalent temperature caused by personalised ventilation from the reference condition as shown in Figure $2 \mathrm{~b}$. The study suggested that future research should consider the development of ATDs that generate airflow with minimum mixing of the personalised air with the polluted room air.
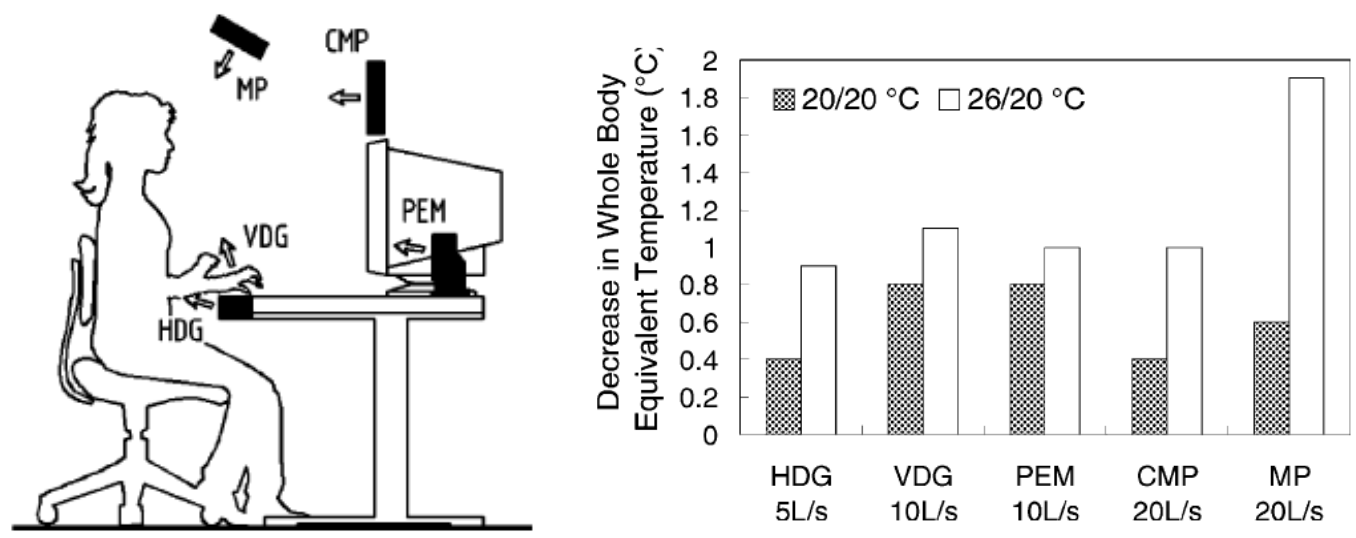

Fig 2. (a) Different types of air terminal devices (ATD): computer monitor panel (CMP), moveable panel (MP) vertical desk grill (VDG), personal environments module (PEM), and horizontal desk grill (VDG) (b) Decrease in the whole-body manikin-based equivalent temperature caused by personalised ventilation from the reference condition (without personalised ventilation) [21] 
Watanabe et al. [22] investigated different designs of an individually controlled system (ICS) equipped with an under-desk air terminal device supplying cool air, desk-mounted personalised ventilation and heating device, as displayed in Figure 3. Experiments were conducted in a climate chamber at various room temperatures. Results showed that the under-desk air terminal device used in the tested ICS did not perform well. It supplied the air against a small body area at the lower chest and therefore did not cool the body efficiently. The maximum cooling effect of the air terminal devices for the whole body was only $0.8^{\circ} \mathrm{C}$ at $26^{\circ} \mathrm{C}$. The study recommended that better design features were needed in order to provide a suitable thermal environmental for the majority of the users and offer comfort to a wider area of the body.

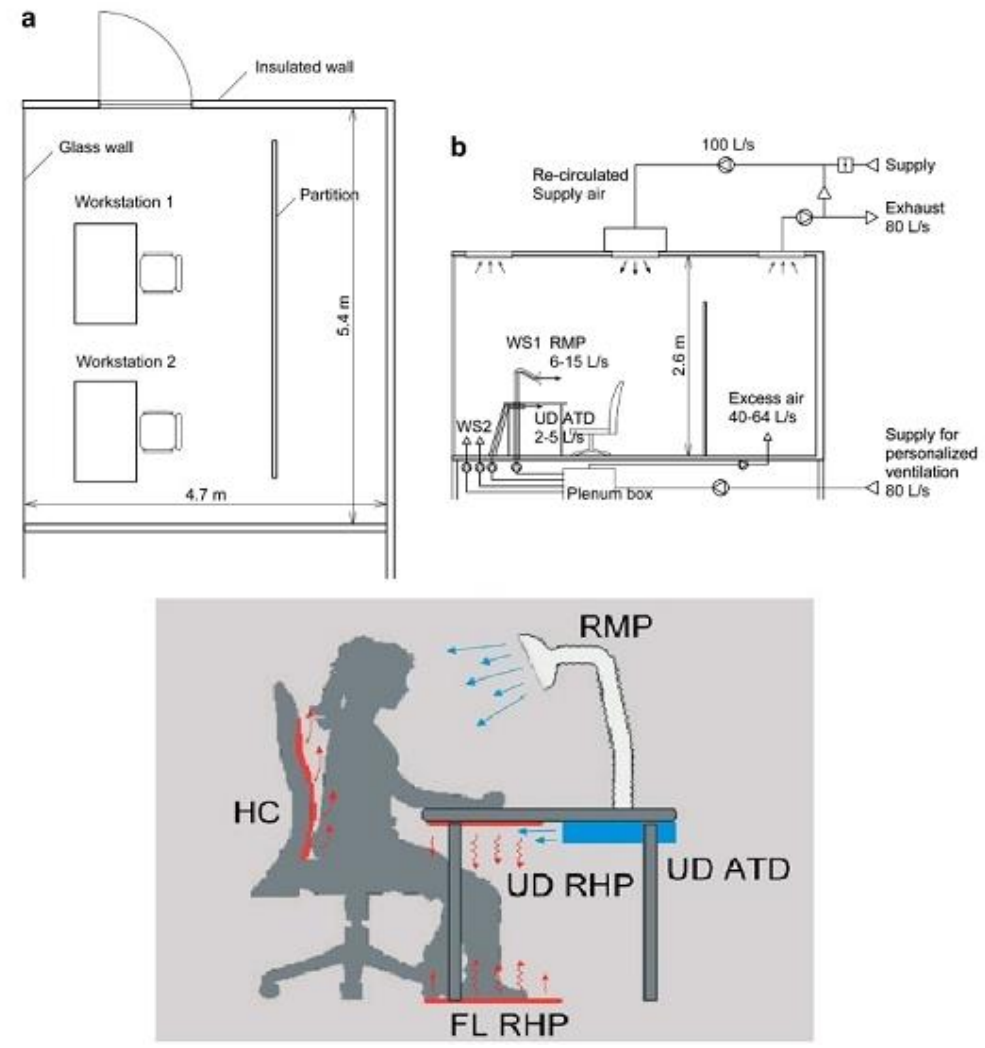

Fig 3. (a) Plan and (b) section of the climate chamber. Schematic design of Individually Controlled System (ICS) equipped with a round movable panel air terminal device (RMP), under task air terminal device (UD ATD), convection heated chair (HC), under desk radiant heating panel (UD RHP), and floor radiant heating panel (FL- RHP) [22]

Conceição et al. [23] focused on the evaluation of air quality level and thermal comfort in a classroom with desks equipped with personalised ventilation devices. Field experiments were conducted in Portugal during the summer months. The design is shown in Figure 4, each personalised ventilation system was installed with one air terminal device (ATD) placed under the desk in front of the occupant's legs while the other one was located at the top of the desk which is in front of the 
occupant's trunk. Results showed that the combined forced convection from the air terminal device and free convection from thermal manikin provides greater airflow around the user.
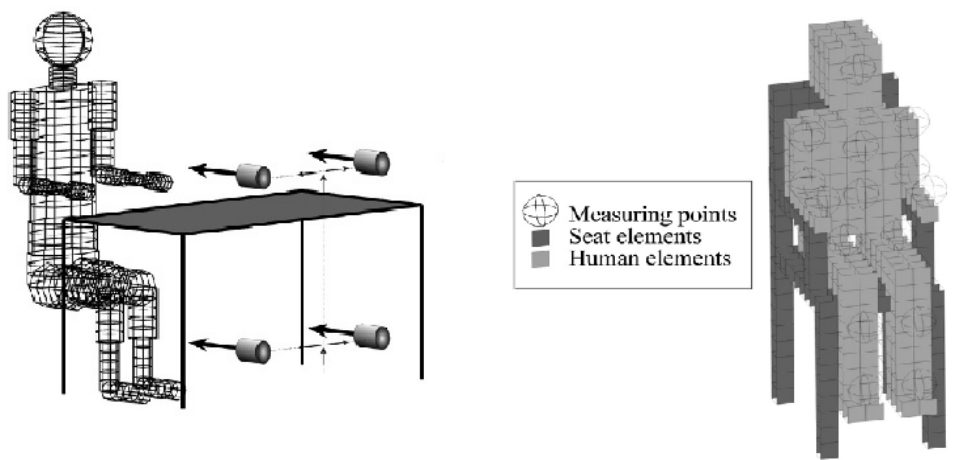

Fig 4. The schematic of the external body shape using multi-nodal human thermal comfort model (left) Geometry of a human body, seat discretisation elements and measuring points (right) [23]

\subsection{Task/air ambient conditioning (TAC System)}

Previous studies indicated that the TAC system can improve energy efficiency and thermal comfort in a wide range of ambient temperatures in an office environment. It provides each occupant significant control of temperature during summer and cold weather conditions. Mao et al. [24] studied a task/ambient air conditioning (TAC) system which was used to optimise the thermal environment and minimise the energy consumption of air conditioning in bedrooms. The work focused on the impact of envelope heat gain on the TAC's energy consumption as shown in Figure 5.

The results showed that at a supply air flow of 50 litres/second, energy consumption was increased from $47.78 \mathrm{~W}$ to $213.11 \mathrm{~W}$ and the predicted mean vote value was increased from -1.69 to -1.29 with the increase in e heat gain from 3.11 Watts to 155.6 Watts.

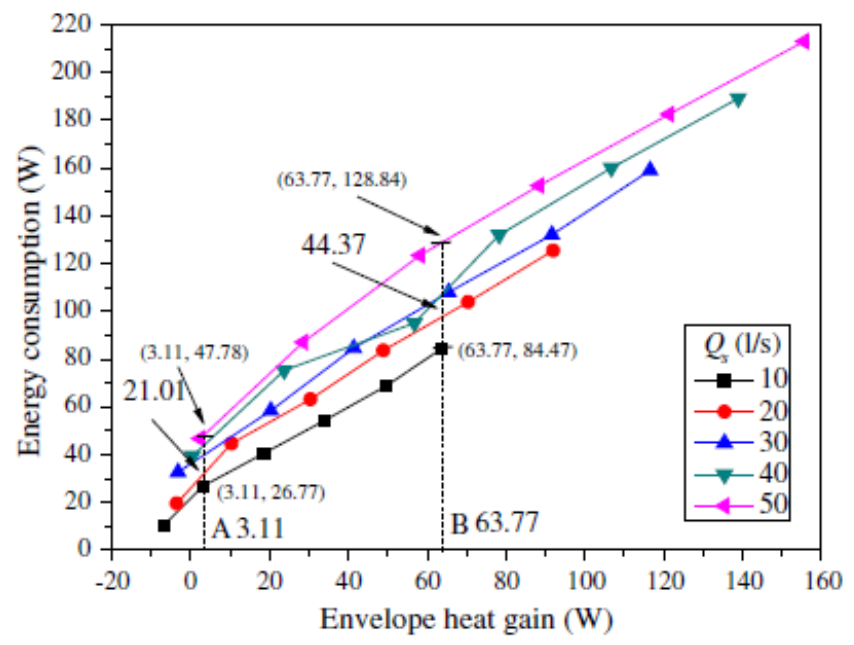

Fig 5. Energy consumption of the task/ambient air conditioning (TAC) system at different supply air flow rate with increasing envelope heat gain [24] 
Zhang et al. [14] proposed a TAC system design which provides heating to the user's hands and feet and cooling to the face and hand in order to provide comfort in a wide range of ambient environment. The experiments involved eighteen subjects in a climatic chamber, tested at a wide range of typical summer and winter conditions. The system provided $40 \%$ energy saving through the reduction of the amount of control needed in an overall standard building.

Tsuzuki et al. [25] investigated three types of TAC systems, including two desk mounted personal environmental module (PEM) for US offices and ClimaDesk (CDESK) for offices in Europe, and Task Air Module (TAM). All three systems provided individual control of cooling while PEM and CDESK also provided individual control of heating. Experiments were conducted in a controlled environment chamber in the University of California, Berkeley. It was observed that although thermal control was slightly reduced at lower airflow rates, significant improvements in ventilation effectiveness were observed when $100 \%$ outside air was supplied through the TAC.
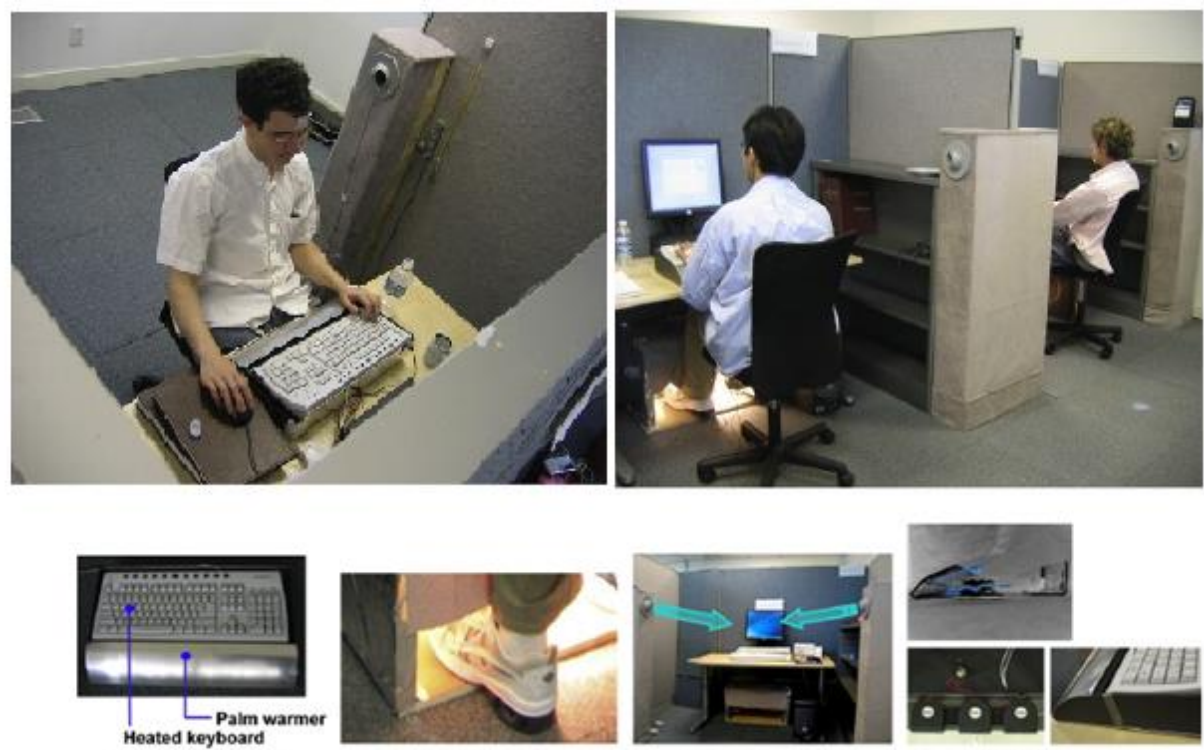

Palm warmer and a heated keyboard

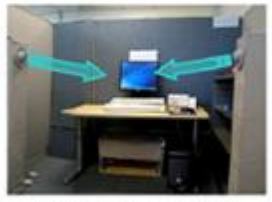

Head ventilation device

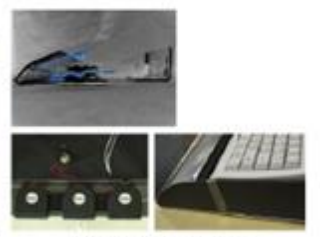

Hand cooling device

Fig 6. First two picture shows 2 workstations installed in the Controlled Environment Chamber to test the two subjects at the same time and picture below demonstrates the four TAC devices [25]

Amai et al. [26] conducted experimental analysis of different types of TAC system which include the non-isothermal airflow (3DU), Personal Environmental Module (PEM), isothermal airflow under-desk task unit (TU), and remote-control unit (RCU), to assess their operation and thermal comfort performance, as shown in Figure 7. The results indicated that the average rating of comfort sensation 
for the TAC systems was between -0.3 and -0.4 for females -0.5 and -0.7 for males. It was found that the parts to which subjects wanted the air to be diffused to were different for each system.
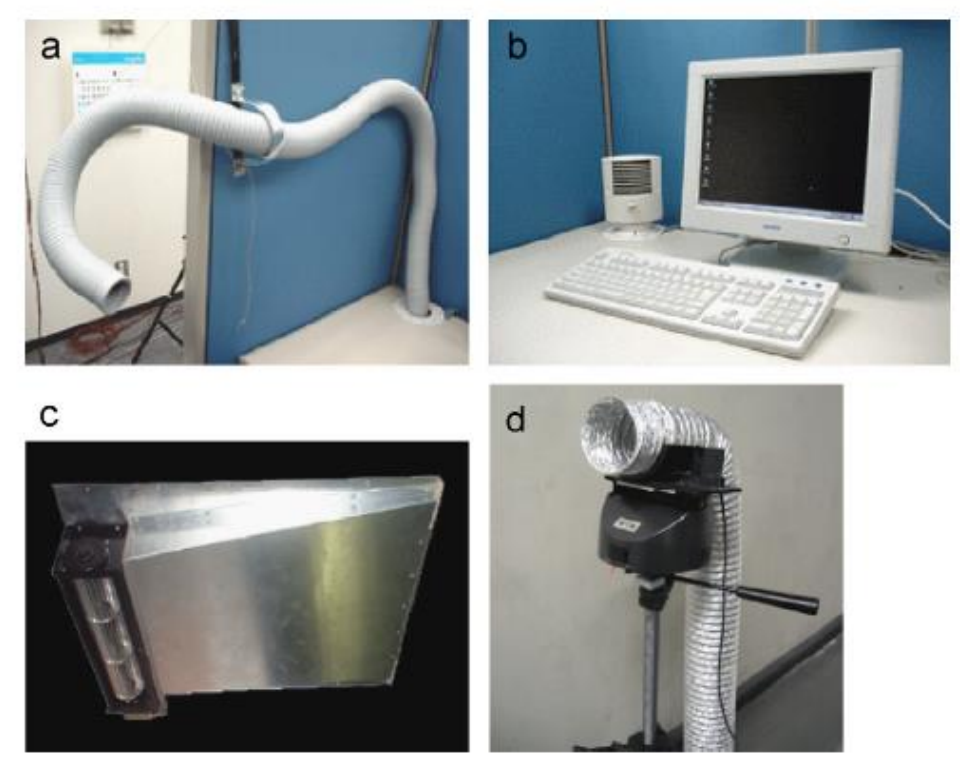

Fig 7. Different types of task/ air ambient conditioning (TAC) system assessed in [26]

\subsection{Personalised ventilation chair}

A chair-based personalised ventilation system is a device which can accommodate the thermal preference of each individual and at the same time improve the quality of air being inhaled by the user. Niu et al. [27] proposed a chair-based personalised ventilation system with an adjustable fresh air supply nozzle positioned directly to the breathing area and the temperature controlled by the occupant. The proposed system can be used in office, lecture halls, cinemas, theatres, and aircrafts, as shown in Figure 8. The study utilised a thermal manikin and subjective measurements to assess the human response. Eight different air terminal devices (ATD) were tested to analyse the fresh air utilisation efficiency and inhaled air quality. Results showed that occupants were more sensitive to the personalised air flow than the personalised air temperature. It was observed that eighty percent of the inhaled air could be composed of fresh personalised air with a supply flow rate of $\leq 3$ litres/s. 


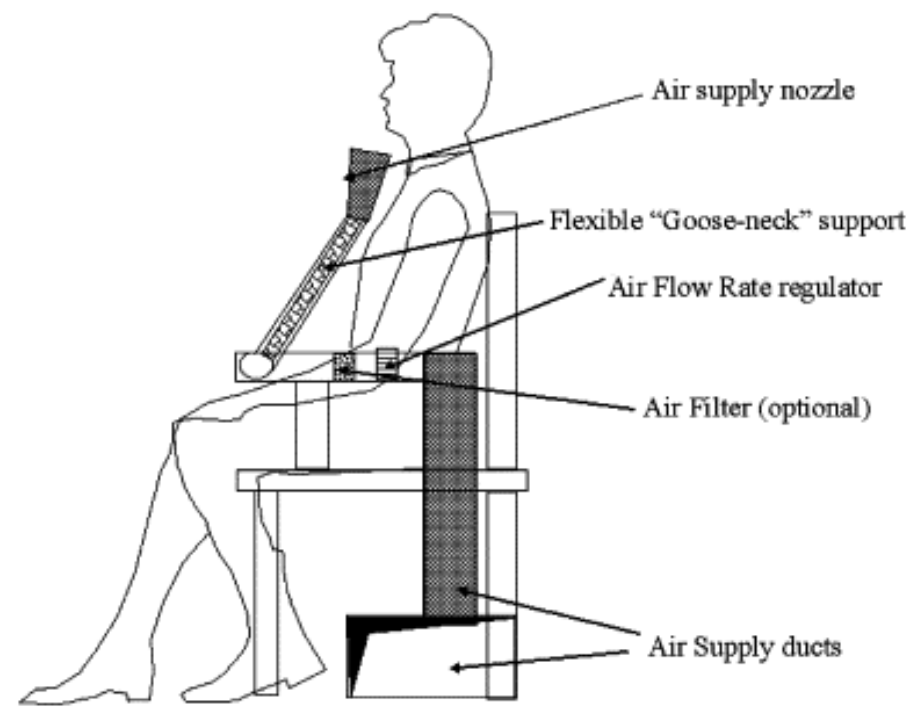

Fig 8. A chair-based personalised ventilation system with adjustable nozzle [27]

On the other hand, Watanabe at al. [28] and Sun et al. [29] study were more focused on incorporating fans under the back rest and seat of the chair. Previous studies have revealed that occupants have reported that direct airflow contact to sensitive parts of the body has not been effective, as it can result in sudden direct airflow in the nose or face which can create an uncomfortable effect to occupants. Watanabe at al. [28] performed subjective experiments during the summer to demonstrate the performance of a chair incorporated with two fans than can provide isothermal forced airflow towards the occupant, as shown in Figure 9. They conducted the experiments in a room with the air temperature set to $26^{\circ} \mathrm{C}, 28^{\circ} \mathrm{C}, 30^{\circ} \mathrm{C}$ and $32^{\circ} \mathrm{C}$ and the users were permitted to control the two built in fans through regulating dials on a desk. Occupants have reported a thermally neutral and comfortable environment regardless of what type of chair was being used for an air temperature of $28{ }^{\circ} \mathrm{C}$. While for a room temperature set at $30^{\circ} \mathrm{C}$, occupants reported that it provided an acceptable thermal environment with regards to comfort and whole body thermal sensation. It also showed great decreased in discomfort rate at the back and lower back where isothermal airflows were directed to. However, the room temperature set at $32^{\circ} \mathrm{C}$ were not successful in providing an acceptable thermal environments for the occupants. 


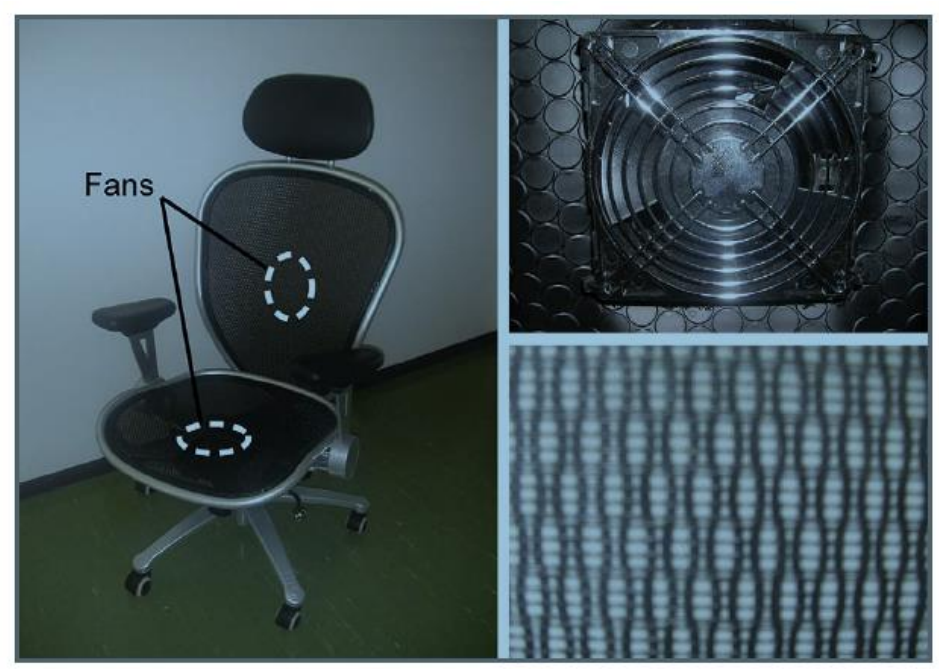

Fig 9. Left picture - test chair with fans equipped behind the backrest and under the seat. Upper right - fan. Lower right - open fabric of the chair [28]

Figure 10 is a design of a chair with four fans attached under the corners of the chair seat proposed by Sun et al. [29]. It allows the cooler air near the floor level to be propelled upward to improve the convection flow around the body parts. Experiments were conducted in Singapore in a controlled climate chamber with displacement ventilation (DV) and same level of heat load at different supply air temperatures between $20^{\circ} \mathrm{C}$ and $24^{\circ} \mathrm{C}$. Thirty-two university students including sixteen males and 16 females participated in the experiment. The students conducted ordinary work during the period of the experiment. The results revealed that the occupants preferred higher air movement and were contented with the cooling offered by the fans in an ambient temperature of $26^{\circ} \mathrm{C}$. But the occupants felt cooler around the waist at $22^{\circ} \mathrm{C}$ and $24^{\circ} \mathrm{C}$ air temperature when the fans were operated. This means that the air movement towards the users could help balance the warm thermal sensation at a high ambient air temperature. 
a
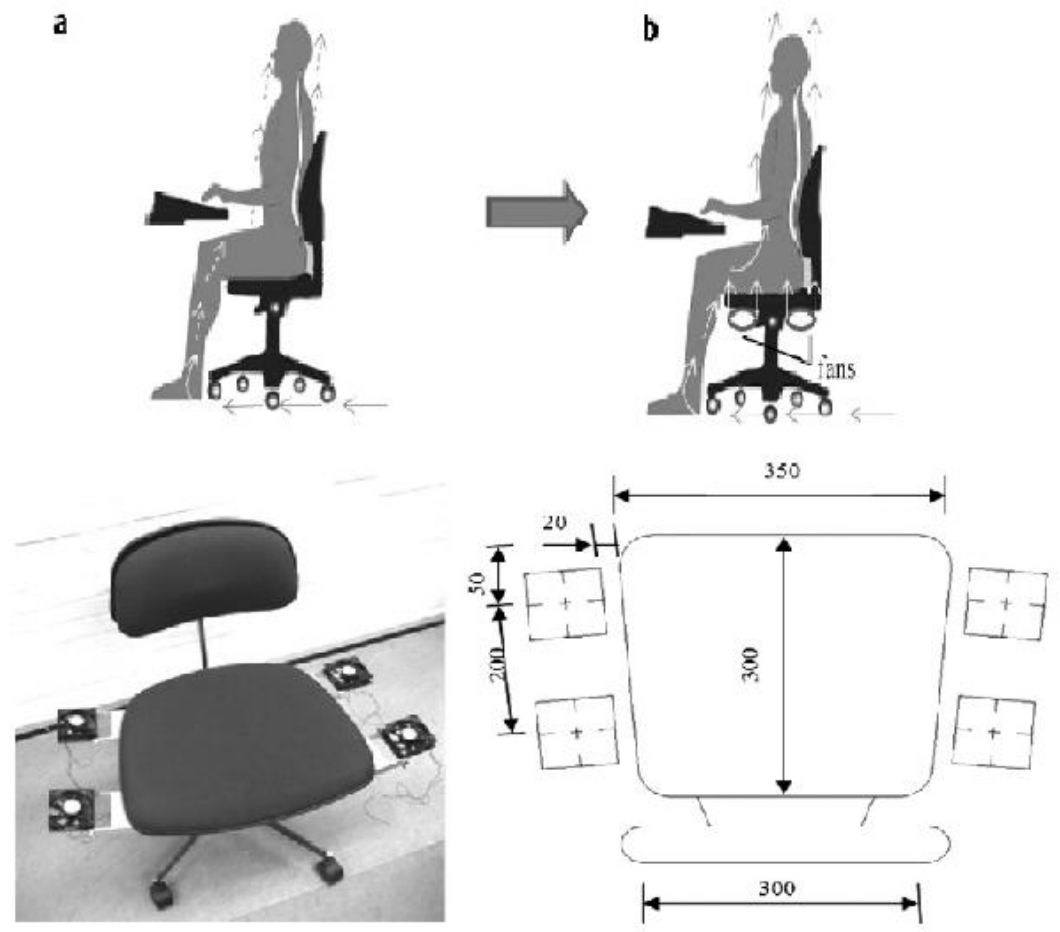

Fig 10. Conventional displacement ventilation (DV) with weak convection flows (a) improved DV with fans (b). Below image demonstrates the actual picture and dimensions of the enhanced conventional DV [29]

\subsection{Cooling and Heating Chair}

A personal comfort system (PCS) chair was proposed by [30] and investigated in an environmental chamber in University of California at Berkeley, USA as shown in Figure 11. Results highlighted the system's potential to offer comfortable conditions during summer and winter conditions. According to the results, the proposed system provided comfortable conditions for more than ninety percent of the subjects in a with a range of temperatures between $18^{\circ} \mathrm{C}$ and $29^{\circ}$, while seventy five percent were comfortable at a temperature of $16^{\circ} \mathrm{C}$. The study concluded that the potential energy reduction for buildings were significant, up to $50 \%$. The PCS energy consumption, which was small as compared to central HVAC's consumption, did not offset the energy saving. 

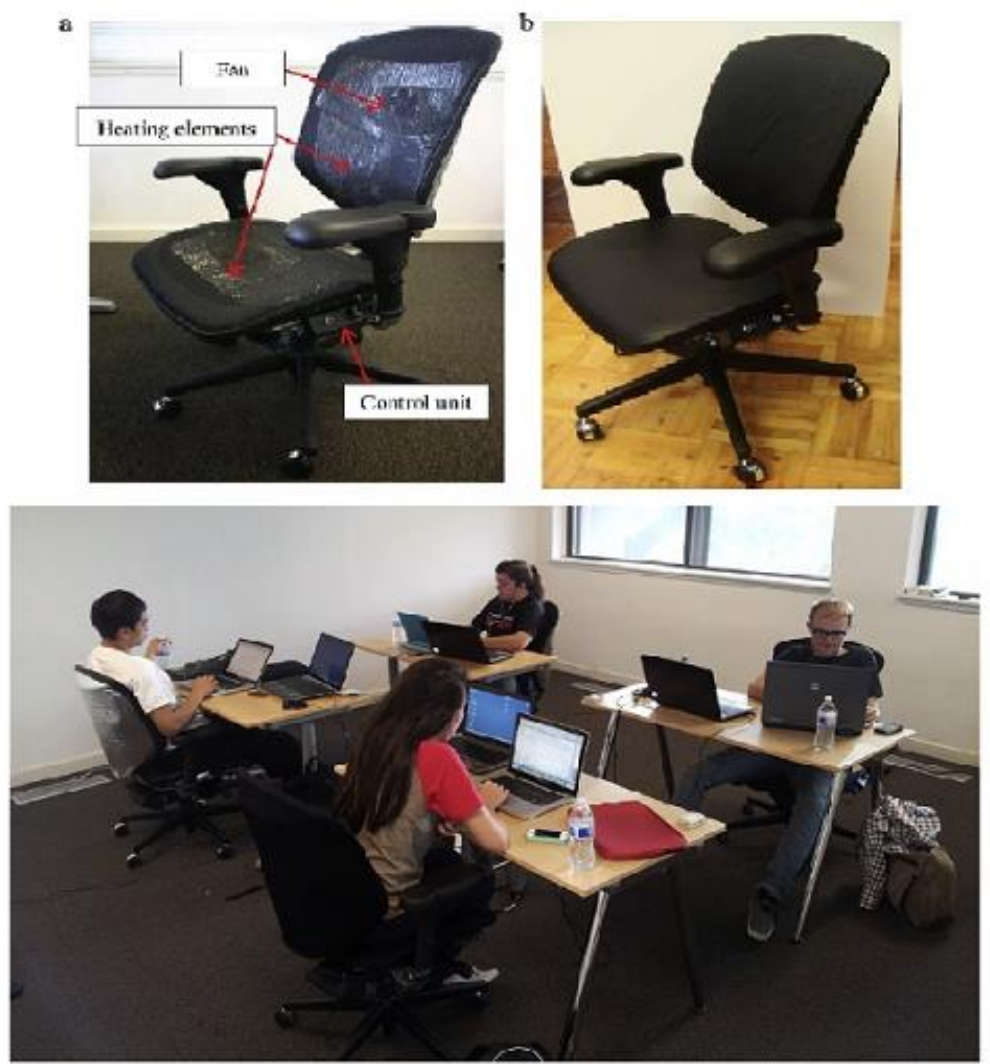

Fig 11. Above picture is an actual image of a (a) mesh personal comfort systems (PCS) chair (b) covered PCS chair. Below demonstrates the actual image of the chamber set up [30].

Pasut et al. [31] examined a chair installed with thermoelectric device (TE) which aims to reduce or increase temperature around the backrest and seat area, as shown in Figure 12. Experiments were conducted in an environmental chamber with the temperature set between $16^{\circ} \mathrm{C}$ and $29^{\circ} \mathrm{C}$. Individuals had full control of the temperature around the chair through a knob placed on the desk. Results have shown that heated/cooled chair provided a great impact on occupants' thermal comfort under both warm and cool tested conditions. In terms of energy consumption, the average power used was 27 watts for $16^{\circ} \mathrm{C}$ while for an ambient temperature of $29^{\circ} \mathrm{C}$, it consumed 45.5 watts. However, the study also concluded that the application of such equipment was currently not an ideal option to replace the traditional HVAC system due to high cost. 


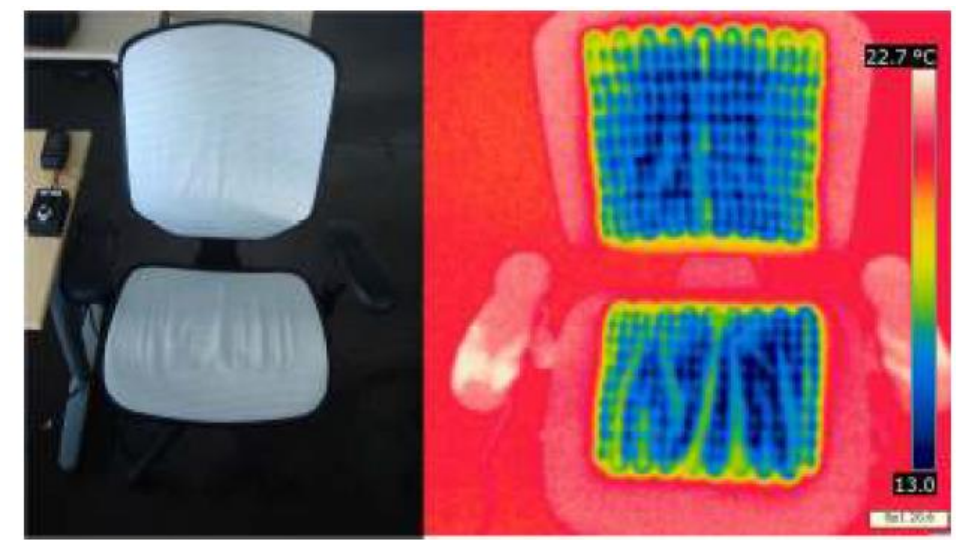

Fig 12. Actual image of the active chair, control knob, and IR image of the chair in operation [31]

Researchers at the Center for Built Environment at UC Berkely have developed a heating and cooling office chair called the Hyperchair [32], it allows occupants to control the device to their desired temperature without affecting other occupants. The chair was incorporated with a heating tape woven into the chair's fabric and installed with fans to warm up the occupant. The temperature can be adjusted by a smartphone app or through pushing a button on the side, as shown in Figure 13. They have reported that the chair can provide 5 to 10 percent of energy savings as individual climate control can possibly turn down the heat or air conditioning. However, the chair is currently sold at a high cost ranging between $\$ 1,000$ to $\$ 1,500$ [32]

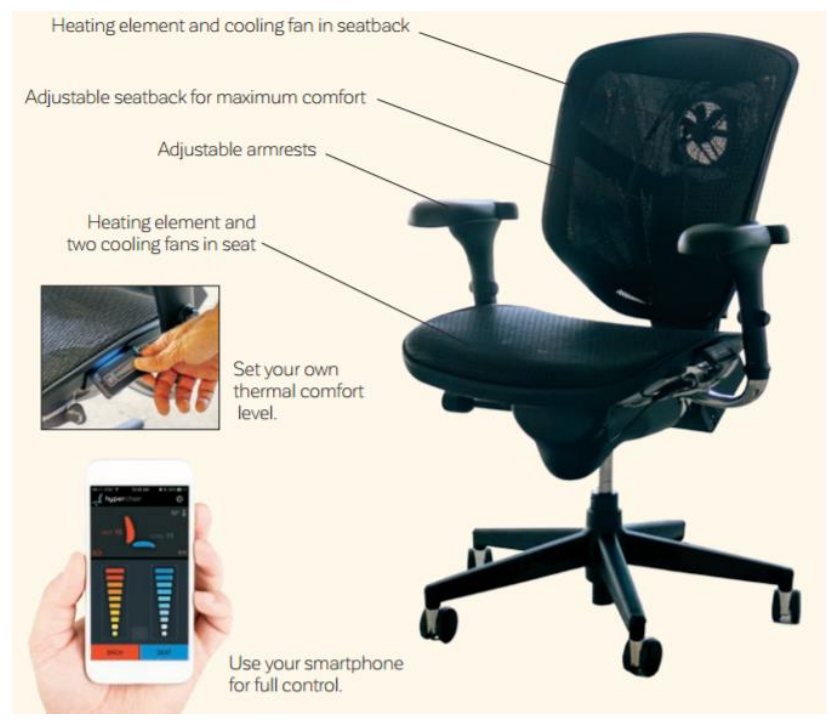

Fig. 13 Design and features of the Hyperchair [32] 
Kogawa et al. [33] examined the performance of cool chairs which was evaluated in two offices in Japan. They have proposed a chair equipped with isothermal generator, as shown in Figure 14. This allows the occupants to control the thermal environment in an office through adjustment of the airflow velocity according to their thermal comfort requirements. They have found that the thermal adjustable cool chair can provide energy conservation, satisfaction to employees in terms of control and thermal comfort.
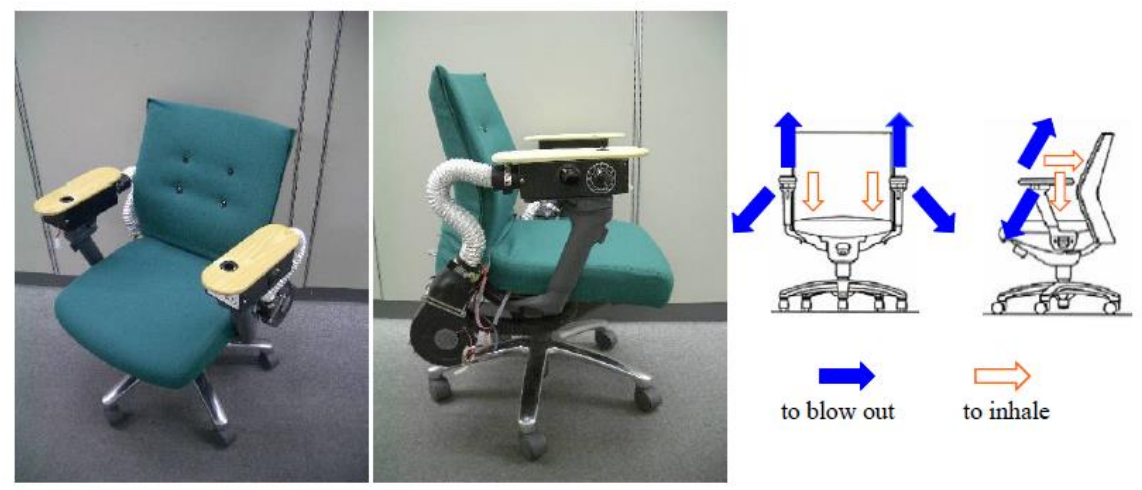

Fig 14. External view and function of the cool chair [33]

Onga et al. [34] conducted subjective experiments using a model that includes behavioural, psychological, physiological adjustments. The experiments were conducted in a climatic chamber. Figure 15 shows the experimental room and type of clothing of subjects with the male clothes thermal resistance at 0.64 clo while the female clothes at 0.65 clo. 18 male and 19 female subjects of college age were involved in the experiments. Results showed that females changed the air flow rate more often as compared to males. The clothes were the reason according to the female subjects. They have also found that subjects felt comfortable using the individual control system.
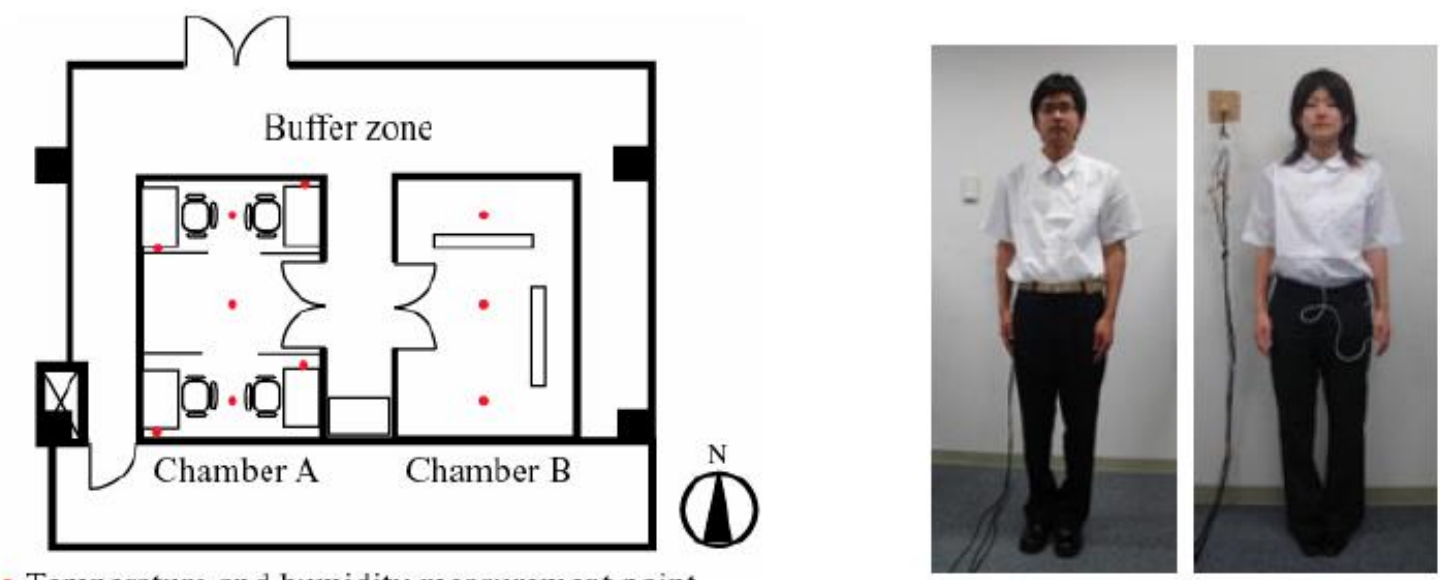

- Temperature and humidity measurement point

Fig 15. Plan of experimental room on subject's clothes [34] 
Table 1 and 2 provides a summary of the reviewed technologies and the advantages and limitations of each system.

Table 1. Summary of the reviewed technologies

\begin{tabular}{|c|c|c|c|c|c|c|c|c|c|}
\hline \multirow[t]{2}{*}{ Reference } & \multicolumn{3}{|c|}{ Functions of the system } & \multicolumn{3}{|c|}{ Type of experiments/evaluation } & \multirow[b]{2}{*}{ Individual control } & \multirow[b]{2}{*}{ Assessed temperature } & \multirow[b]{2}{*}{ Energy consumption/saving } \\
\hline & Heating & Cooling & Ventilation & $\begin{array}{c}\text { study (number } \\
\text { of subjects) }\end{array}$ & $\begin{array}{l}\text { Thermal } \\
\text { manikin }\end{array}$ & Simulations & & & \\
\hline $\begin{array}{l}\text { Ning et al. } \\
(2017)\end{array}$ & $\checkmark$ & $\checkmark$ & $\checkmark$ & - & $\checkmark$ & $\checkmark$ & Flow rate of the personalised air & $24-30^{\circ} \mathrm{C}$ & $\begin{array}{l}\text { Energy consumption of TAC system depends only on } \\
\text { the envelope heat gain - } 1.31 \mathrm{~W} \text { per Watt of envelope } \\
\text { heat gain. }\end{array}$ \\
\hline Niu et al. (2005) & $\checkmark$ & $\checkmark$ & $\checkmark$ & - & $\checkmark$ & $\checkmark$ & Flow rate under some conditions of personalised air & $23,36,29^{\circ} \mathrm{C}$ & - \\
\hline $\begin{array}{l}\text { Amai et al. } \\
\text { (2006) }\end{array}$ & $\checkmark$ & $\checkmark$ & $\checkmark$ & $\boldsymbol{V}_{(24)}$ & - & - & Flow rate under some conditions of personalised air & $26-28^{\circ} \mathrm{C}$ & - \\
\hline $\begin{array}{l}\text { Watanabe et al. } \\
\text { (2008) }\end{array}$ & & $\checkmark$ & $\checkmark$ & $\checkmark_{(7)}$ & - & - & Fan speed & $26-32{ }^{\circ} \mathrm{C}$ & - \\
\hline $\begin{array}{l}\text { Zhang et al. } \\
\text { (2009) }\end{array}$ & $\checkmark$ & $\checkmark$ & $\checkmark$ & $\boldsymbol{V}_{(18)}$ & - & - & $\begin{array}{l}\text { Flow rate of the personalised air, palms and feet heating levels and } \\
\text { cooling on the face and back }\end{array}$ & $18-30^{\circ} \mathrm{C}$ & $\begin{array}{l}\text { The system's peak wattage for cooling was } 41 \mathrm{~W} \text {, and } \\
\text { for heating at steady state was at } 59 \mathrm{~W} \text {. Average } \\
\text { annual energy saving of TAC system for } 3 \text { different } \\
\text { cities was at } 27-44 \text { percent with interior temperature } \\
\text { range of } 18-30^{\circ} \mathrm{C} \text {. }\end{array}$ \\
\hline $\begin{array}{l}\text { Watanabe et al. } \\
\text { (2009) }\end{array}$ & $\checkmark$ & $\checkmark$ & - & - & $\checkmark$ & $\checkmark$ & $\begin{array}{l}\text { Fow rate and direction of the personalised air under desk airflow } \\
\text { rate, the temperature of the convection flow from the chair, and } \\
\text { surface temperature of heating panels. }\end{array}$ & $20-26^{\circ} \mathrm{C}$ & - \\
\hline $\begin{array}{l}\text { Conceição et } \\
\text { al. (2009) }\end{array}$ & $\checkmark$ & & $\checkmark$ & & $\checkmark$ & $\checkmark$ & Flow rate under some conditions of personalised air & $28^{\circ} \mathrm{C}$ & - \\
\hline $\begin{array}{l}\text { Sun et al. } \\
\text { (2012) }\end{array}$ & $\checkmark$ & $\checkmark$ & $\checkmark$ & $\boldsymbol{V}_{(32)}$ & & & Fan speed & $20-26{ }^{\circ} \mathrm{C}$ & $\begin{array}{l}\text { Energy consumption - a power consumption of each } \\
\text { fluorescent lamp was } 36 \mathrm{~W} \text {. }\end{array}$ \\
\hline $\begin{array}{l}\text { Pasut et al. } \\
\text { (2014) }\end{array}$ & $\checkmark$ & $\checkmark$ & $\checkmark$ & $\boldsymbol{V}_{(23)}$ & - & - & $\begin{array}{l}\text { Fllow rate and direction of the personalised air under desk airflow } \\
\text { rate, the temperature of the convection flow from the chair, and } \\
\text { surface temperature of heating panels. }\end{array}$ & $18-29^{\circ} \mathrm{C}$ & $\begin{array}{l}\text { The chair system's maximum power was } 4.8 \mathrm{~W} \text { for } \\
\text { cooling ( } 3.6 \mathrm{~W} \text { for the chair plus } 1.2 \mathrm{~W} \text { for the desk fan) } \\
\text { and } 16 \mathrm{~W} \text { for heating, and power is drawn only when } \\
\text { occupied. }\end{array}$ \\
\hline $\begin{array}{l}\text { Melikov et al. } \\
\text { (2002) }\end{array}$ & $\checkmark$ & $\checkmark$ & $\checkmark$ & & $\checkmark$ & $\checkmark$ & No control & 20 and $26^{\circ} \mathrm{C}$ & - \\
\hline $\begin{array}{l}\text { Kogawa et al. } \\
\text { (2007) }\end{array}$ & - & - & $\checkmark$ & $\checkmark_{(8)}$ & - & - & Flow rate of the personalised air & $22-30^{\circ} \mathrm{C}$ & - \\
\hline
\end{tabular}




\begin{tabular}{|c|c|c|c|c|c|c|c|c|c|}
\hline $\begin{array}{l}\text { Onga et al. } \\
\text { (2002) }\end{array}$ & - & - & $\checkmark$ & $\checkmark_{(37)}$ & - & - & Flow rate of the personalised air & $28-33.4^{\circ} \mathrm{C}$ & - \\
\hline $\begin{array}{l}\text { Wilmer et al. } \\
\text { (2013) }\end{array}$ & $\checkmark$ & - & $\checkmark$ & $\checkmark_{(16)}$ & - & - & Flow rate of the personalised air & $16,18,25,29^{\circ} \mathrm{C}$ & $\begin{array}{l}\text { The average power drawn was } 27 \text { Watts at } 16^{\circ} \mathrm{C}(60.8 \\
\left.{ }^{\circ} \mathrm{F}\right) \text {, and } 45.5 \text { Watts at } 29{ }^{\circ} \mathrm{C} \text { ambient conditions } \\
\left(84.2^{\circ} \mathrm{F}\right) \text {. }\end{array}$ \\
\hline $\begin{array}{l}\text { Tzuki et al. } \\
\text { (1999) }\end{array}$ & $\checkmark$ & & $\checkmark$ & & $\checkmark$ & $\checkmark$ & Flow rate of the personalised air & $19-25^{\circ} \mathrm{C}$ & - \\
\hline $\begin{array}{l}\text { Bauman et al. } \\
\text { (2015) }\end{array}$ & $\checkmark$ & - & $\checkmark$ & $\checkmark_{(16)}$ & - & - & Flow rate and direction of the personalised air & $20,25,20^{\circ} \mathrm{C}$ & $\begin{array}{l}\text { Zone heating energy savings ranged from } 46 \text { to } 75 \\
\text { percent, depending on the set point of the } \\
\text { temperature and outdoor weather conditions. }\end{array}$ \\
\hline $\begin{array}{l}\text { Halvon ova and } \\
\text { Melikov (2009) }\end{array}$ & - & $\checkmark$ & $\checkmark$ & & $\checkmark$ & $\checkmark$ & Flow rate of the personalised air & $18-20^{\circ} \mathrm{C}$ & - \\
\hline
\end{tabular}

Table 2. Comparison of the different personalised comfort systems

\begin{tabular}{|c|c|c|c|}
\hline Personalised comfort system & Advantages & Disadvantages & Recommendations \\
\hline Task/ambient air conditioning & $\begin{array}{l}\text { - } \quad \text { Better ventilation system } \\
\text { - Thermal comfort in a wide range of ambient temperatures } \\
\text { in a room } \\
\text { Individual control of the system - providing significant } \\
\text { control of heat offset to each occupant during summer and } \\
\text { cold weather conditions } \\
\text { - } \quad \text { Air is only chilled where it is needed } \\
\text { - Reduce energy consumption }\end{array}$ & $\begin{array}{l}\text { - TAC systems are very expensive and difficult to install } \\
\text { after initial construction } \\
\text { - The amount of cooling is dependent primarily on the } \\
\text { air supply volume and direction, and to a lesser } \\
\text { degree on the supply air temperature }\end{array}$ & $\begin{array}{l}\text { - Better design properties } \\
\text { - Cost of installation must take into consideration } \\
\text { - Better construction }\end{array}$ \\
\hline Air Terminal Device (ATD) & $\begin{array}{l}\text { - Different individual control systems on the chair, desk, } \\
\text { floor level, and air directed towards the face of the } \\
\text { occupants } \\
\text { - } \quad \text { Air is only chilled where it is needed } \\
\text { - } \quad \text { Reduce energy consumption } \\
\text { Can supply conditioned fresh air directly into the breathing } \\
\text { zone which avoids the process of mixing with } \\
\text { contaminants or old air in a room }\end{array}$ & $\begin{array}{l}\text { - Combination of different ATD's result in higher air } \\
\text { temperature, higher air room temperature result in a } \\
\text { lower heating performance of each and combined } \\
\text { heating system } \\
\text { - Sudden blow of airflow from the device - especially } \\
\text { to the sensitive parts like face or nose can result in } \\
\text { irritation or sickness }\end{array}$ & $\begin{array}{l}\text { - Minimum combination of the personalised air } \\
\text { with polluted room air was better for further } \\
\text { improvement of the ATD result in reduction of } \\
\text { energy consumption } \\
\text { - Better design properties } \\
\text { - Individual control systems tend to be adjusted } \\
\text { repeatedly which can damage the device or may } \\
\text { result in overheating }\end{array}$ \\
\hline
\end{tabular}




\begin{tabular}{|c|c|c|c|}
\hline Personalised ventilation chair & $\begin{array}{l}\text { - Acceptable thermal environments in regard to comfort, } \\
\text { acceptable chair equipped with fans and whole body } \\
\text { thermal sensation } \\
\text { - Showed great decreased in discomfort rate at the back and } \\
\text { lower back where isothermal airflows were directed to } \\
\text { - Allows the cool air near the floor level and improves the } \\
\text { convection flow around the body parts } \\
\text { Reduce energy consumption }\end{array}$ & $\begin{array}{l}\text { - Limited air room temperature was successful in } \\
\text { providing acceptable thermal environments for the } \\
\text { occupants } \\
\text { - Energy saving was quite not significantly offset with } \\
\text { the energy consumption of the chair and it was little } \\
\text { as compared with the central heating, ventilation air } \\
\text { condition (HVAC) system } \\
\text { - Application of thermoelectric on chairs cost many } \\
\text { times more compared to the energy it will save } \\
\text { - Thermal sensation under the buttocks and thighs } \\
\text { have been reported to be warmer while colder on } \\
\text { the back when there is only one individual control for } \\
\text { the back and seat area. }\end{array}$ & $\begin{array}{l}\text { - Improved design that can be applied in theatres } \\
\text { and lecture hall } \\
\text { - Occupants' movement and body posture must } \\
\text { always be considered in conducting subjective } \\
\text { experiments as it affects the effectiveness of the } \\
\text { chair } \\
\text { - Better design properties } \\
\text { - Better construction }\end{array}$ \\
\hline Cool Chair & $\begin{array}{l}\text { - Thermal adjustable cool chair can provide energy } \\
\text { conservation, satisfaction to employees in feeling control, } \\
\text { and thermal comfort } \\
\text { - The amount and direction of airflow are easily adjusted }\end{array}$ & $\begin{array}{l}\text { - Facial dryness } \\
\text { - Controller of the cool chair is battery operated that } \\
\text { requires several hours to charge and chair is plugged } \\
\text { with a cord into an electrical outlet after office hours }\end{array}$ & - Better design properties \\
\hline
\end{tabular}




\section{Research Methodology}

This study aims to improve user comfort through the application of a thermal chair in the workplace. It investigated the application of Computational Fluid Dynamics (CFD), Building Energy Simulation (BES) and field studies of thermal comfort to analyse the performance of a thermal chair used in an open plan office. A prototype of an office chair equipped with separate user temperature control over the seat and the back was designed and produced, as illustrated in Figure. The chair seat and the back rest areas was incorporated with heating element pads covered by the chair fabric. Each pad uses up to $30 \mathrm{~W}$. Surface temperature measurements in Figure (left) shows the typical temperature at various settings: $30 \%$ (low), $60 \%$ (medium) and 100\% (high) while the corresponding average energy usage are shown in Figure (right).
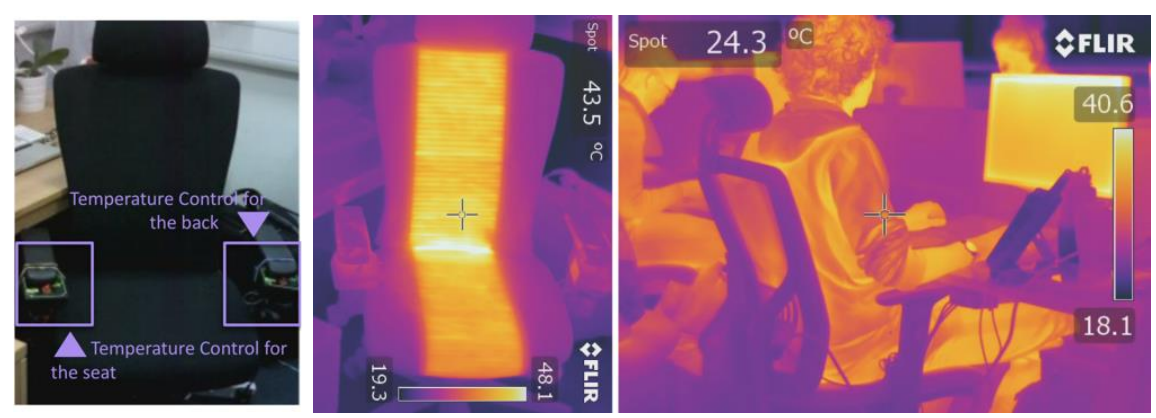

Figure 16. Thermal chair: (left) design, (middle) thermal image of seat temperature (FLIR T660) and (right) in use
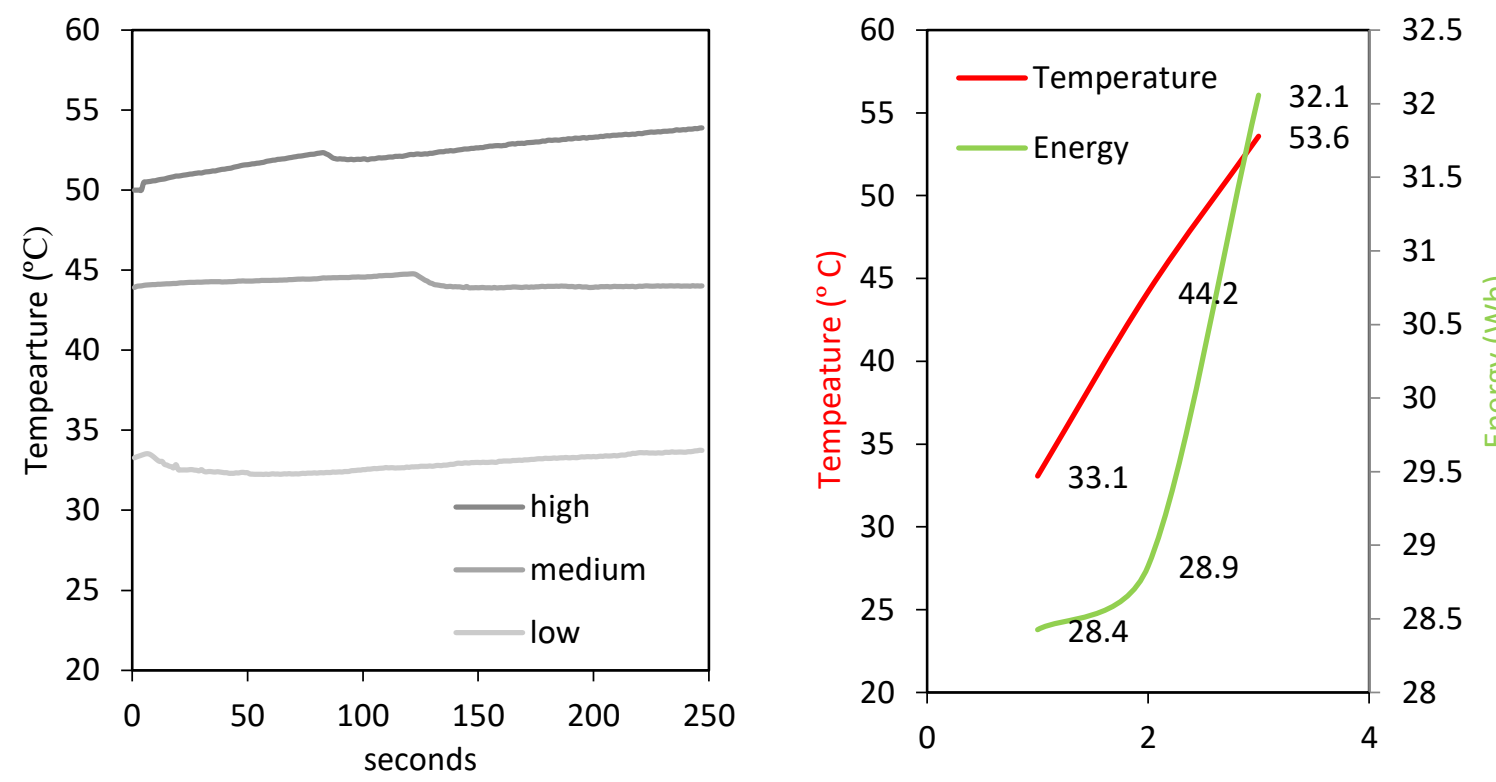

Figure 17. (left) Thermocouple temperature measurements of the surface of heating element pads and (right) average temperature and energy measurements at various settings. 
The basic assumptions for the numerical simulation include a 3D, fully turbulent, and incompressible flow. The numerical CFD code was used with the Finite Volume Method (FVM) approach and the SemiImplicit Method for Pressure-Linked Equations (SIMPLE) velocity-pressure coupling algorithm with the second order upwind discretisation. The k-epsilon transport model was employed for the air turbulence due to its well-documented performance in predicting indoor airflows $[35,36]$. The general governing equations include the continuity, momentum and energy balance for each individual phase. The transport equations are not repeated here but are fully available in [37].

The geometry (Figure ) was created using commercial CAD software and then imported into ANSYS to create a computational model. In this study a sitting manikin was used to analyse the impact of the thermal chair on the prediction of airflow velocity and temperature field. Figure shows the geometry of the thermal chair with the manikin (1.8m standing height) inside the computational domain $(4.8 \mathrm{~m}$ width $\times 3.8 \mathrm{~m}$ length $\times 3 \mathrm{~m}$ height) representing a region in the open plan office. The computational domain consisted of an inlet on one side of the domain, and an outlet on the opposing boundary wall with the thermal chair located centrally.

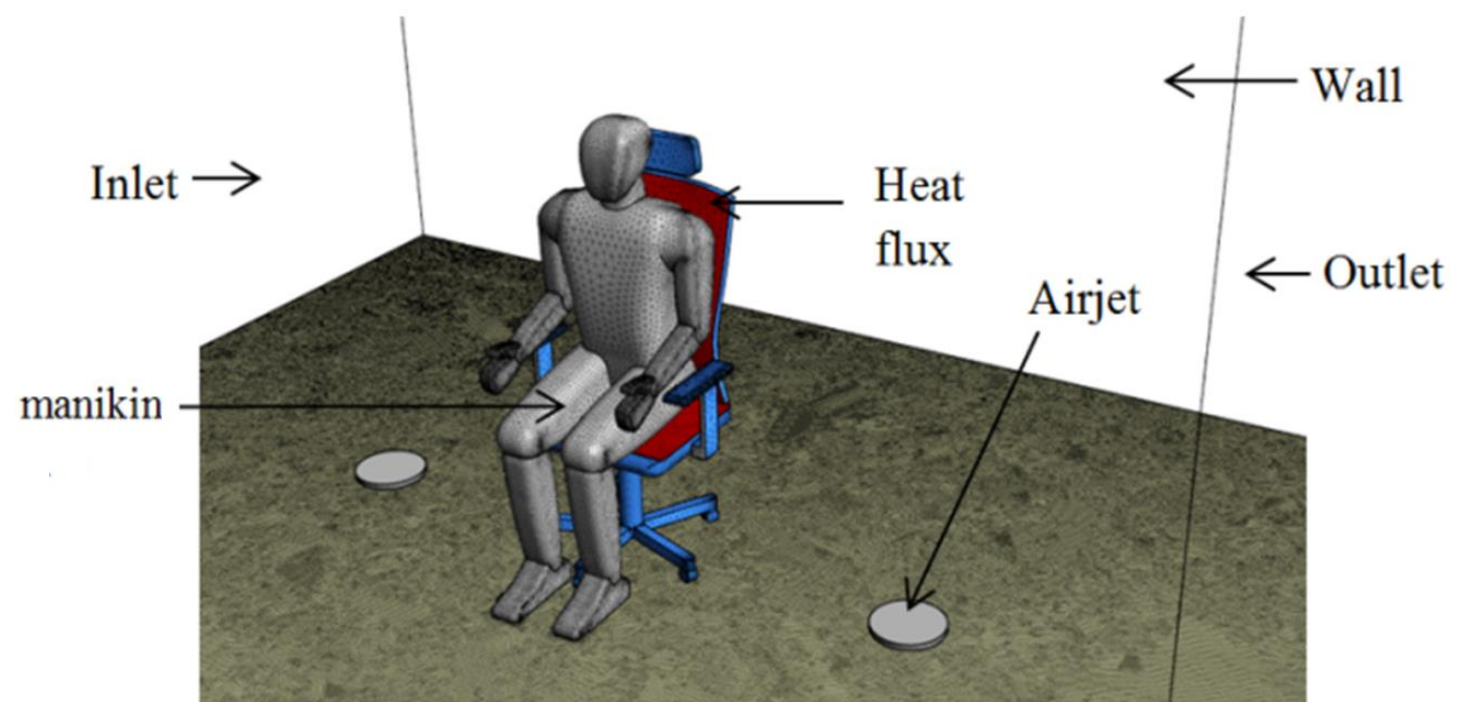

Figure 18. Computational domain for the analysis of office thermal chair with manikin model

Due to the complexity of the model, a non-uniform mesh was applied to volume and surfaces of the computational domain $[37,38]$. The generated computational mesh is shown in Figure. The mesh was modified and refined according to the critical areas of interests in the simulation $[39,40]$. The size of the mesh element was extended smoothly to resolve the areas with high gradient mesh and to improve the accuracy of the results [41]. Sensitivity analysis was used to verify the computational modelling of the thermal chair with manikin [42]. The sensitivity analysis was performed by conducting additional simulations with same domain and boundary conditions but with various mesh sizes 
(coarse, medium and fine mesh). The average value of the airflow velocity in the vertical line was used as the error indicator (Figure ). The average error between the fine and coarse mesh was $5.4 \%$ or $\pm 0.032 \mathrm{~m} / \mathrm{s}$. Thus, the repetition of numerical model with finer mesh had no considerable effects on the results.

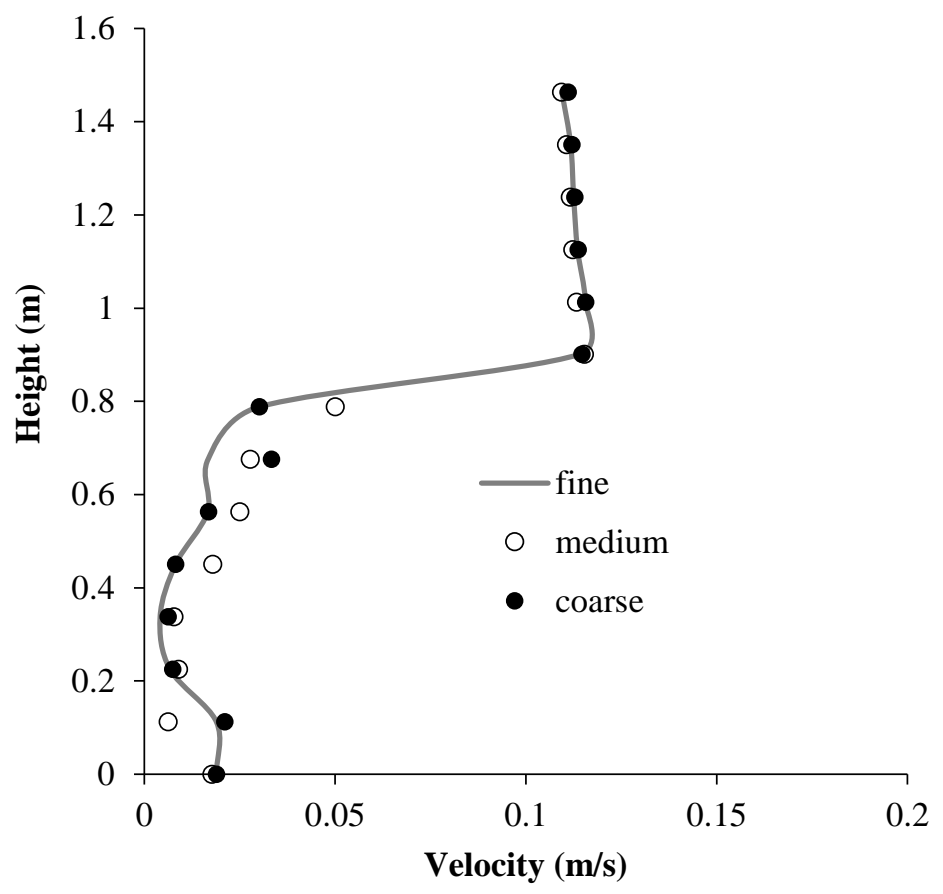

Figure 19. Grid sensitivity analysis

The convergence of the solution and relevant variables were monitored and the solution was completed when there were no changes between iterations. In addition, the property conservation was also checked if achieved. This was carried out by performing a mass flux balance for the converged solution. This option was available in the FLUENT flux report panel which allows computation of mass flow rate for boundary zones. For the current simulation, the mass flow rate balance was below the required value or $<1 \%$ of smallest flux through domain boundary (inlet and outlet).

As shown in Figure 18, one side of the computational domain was set as velocity inlet (set at $0.1 \mathrm{~m} / \mathrm{s}$ and $23^{\circ} \mathrm{C}$ ) and the opposite wall as pressure outlet. Two configurations were simulated; (a) an office chair with heated seat (heat flux: $40 \mathrm{~W} / \mathrm{m} 2$ ) and back rest (heat flux: $40 \mathrm{~W} / \mathrm{m} 2$ ) and (b) a standard non-heated office chair and $250 \mathrm{~mm}$ diameter underfloor air jets (set at $0.2 \mathrm{~m} / \mathrm{s}$ and $25^{\circ} \mathrm{C}$ ). The examination of the thermal chair and regular chair was based on the actual case study office building which had underfloor air distribution as part of the building design ( 2 air jets per seat). The set inflow conditions based on actual measurement (Testo425). The airflow in the horizontal direction was set to represent the average airflow movement in the office $(0.1 \mathrm{~m} / \mathrm{s})$ which was also based on the actual 
measurement (Testo425). The surface facing the back of the chair was set as a wall and the surface opposite was set as a symmetry wall. It should be noted that the distance from the back of the manikin to the wall, represents the actual distance in the case study between the person and the wall while the distance between the person and top wall also represents the actual distance between the user and the ceiling in the office. In the actual case study office, the user was sat opposite to another person and therefore the symmetry boundary condition was used. This allows the simulation study to focus on a single region in the office space, providing a detailed analysis of single chair and occupant, and at the same time reduces the computational resource and time required i.e. as compared to a full open plan office simulation. It should be noted that the manikin in the study was only intended to replicate the physical shape of a sitting person. The heat released by the manikin on the surrounding airflow field was also simulated by applying a heat load (a total heat load of $89 \mathrm{~W}$ ) at the manikin surface $[43,44]$, while the radiation was not explicitly modelled in this study. However, the mean radiant temperature was included in the PMV calculation which was calculated using surface temperatures and the ASHRAE Thermal Comfort Tool 2. The work of [34] details the impact of simplified methods on thermal airflow fields in the vicinity of surfaces.

\subsection{Building Energy Simulation (BES) modelling}

The models of the office building based on [45] and the thermal chair were created in the commercial Building Energy Simulation (BES) software, IES Virtual Environment 2017 and simulated by using a similar weather file [45], London Gatwick weather file for validation purposes. The three-story office building used for the analysis is a narrow open plan office building with the dimensions $32 \mathrm{~m}$ (length) and $16 \mathrm{~m}$ (width) and floor to ceiling height of 3.5, as shown in Figure 20. Each floor was split into two zones, office zone and common areas zone. For simplification, the ground floor model was identical to the first and second floor. The open plan office zone consisted of a large open space (Zone 1) and a common area zone (Zone 2) which represents toilets, reception, corridors, circulation, etc. The zones were represented as separate thermal zones. Overall, the building had a floor area of $1536 \mathrm{~m}^{2}$ and external wall area of $1008 \mathrm{~m}^{2}, 50 \%$ covered with glazing. The building elements materials were set to conform to current national standards in the UK [46] and latest best practice constructions with significantly lower U-values as compared to standard requirements as detailed in 3 . Solar heat gain coefficient (SHGC) for the glazing was 0.637 while the visible transmittance was 0.761 [45]. 


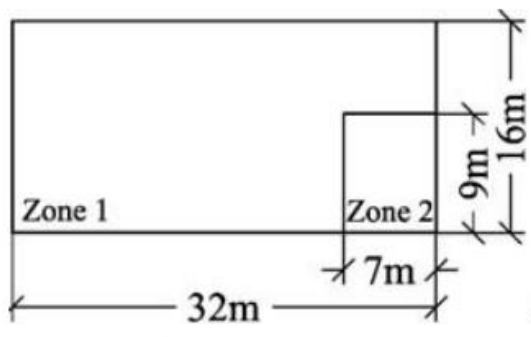

Open plan

Total Floor Area: $1536 \mathrm{~m}^{2}$

Ext Wall Area: $1008 \mathrm{~m}^{2}$

Glazing Area: $504 \mathrm{~m}^{2}$

Total Volume: $5376 \mathrm{~m}^{3}$

Location: London/Gatwick, UK

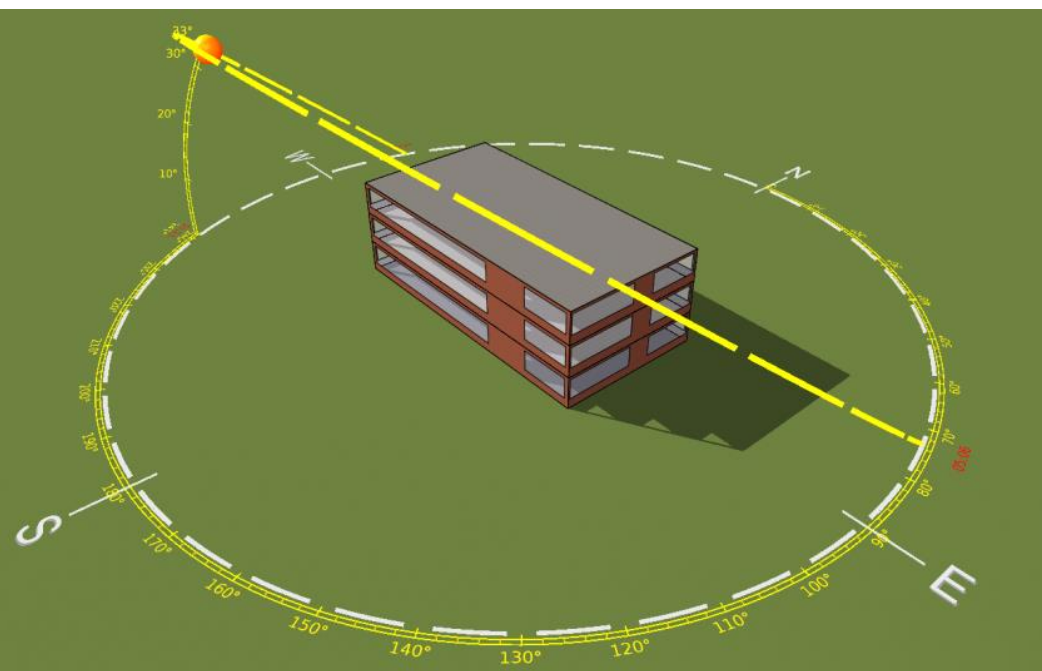

Figure 20. Office plan office building model and floor plan based on the study of [45]

Table 3. $U$-values of the building fabric components [45]

\begin{tabular}{|c|c|}
\hline Fabric component & $\boldsymbol{U}$-value $\left(\mathbf{W} /\left(\mathbf{m}^{\mathbf{2}} \mathbf{K}\right)\right)$ \\
\hline Wall (external) & 0.25 \\
\hline Roof (flat) & 0.15 \\
\hline Ground & 0.15 \\
\hline Windows & 1.78 \\
\hline
\end{tabular}

The building's location was London/Gatwick, UK and the annual weather data is detailed in Figure 21, which was obtained from ASHRAE design weather database v5.0. Ground reflectance was set 0.20 for both summer and winter. Terrain type was assumed to be city. The wind exposure was set to normal. 

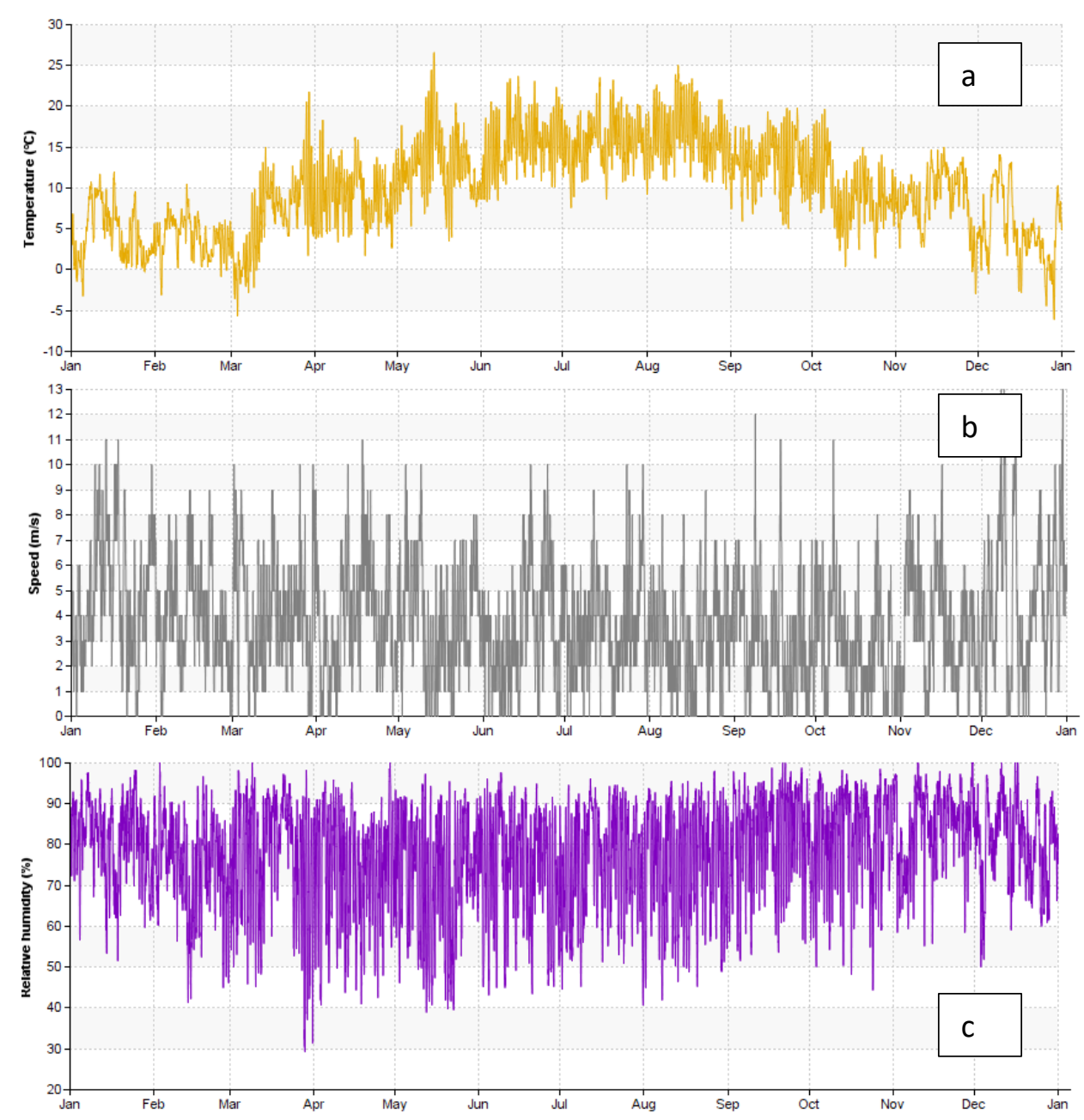

Figure 21 Weather data: (a) Dry-bulb temperature $\left({ }^{\circ} \mathrm{C}\right)(\mathrm{b})$ wind speed $(\mathrm{m} / \mathrm{s})(\mathrm{c})$ relative humidity $(\%)$

The open plan type office building was assumed to have the following occupancy pattern: 7:00 to 19:00 during weekdays and close during weekend. The indoor thermal and ventilation conditions were closely controlled based on set profiles during the occupancy period: the office space (Zone 1) was kept at $22^{\circ} \mathrm{C}$ during heating period and at $24^{\circ} \mathrm{C}$ during cooling period and the common area (Zone 2) was kept at $20^{\circ} \mathrm{C}$ during heating period and at $26^{\circ} \mathrm{C}$ during cooling period, as detailed in Figure $22 \mathrm{a}$ and $\mathrm{b}$. The temperature in both the zones were maintained at $12^{\circ} \mathrm{C}$ during unoccupied hours and in order to prevent overheating, cooling was turned on if temperature reaches $28^{\circ} \mathrm{C}$ in Zone 1 and $30^{\circ} \mathrm{C}$ in Zone 2, as per values recommended by the CIBSE and ASHRAE guidelines [47] 


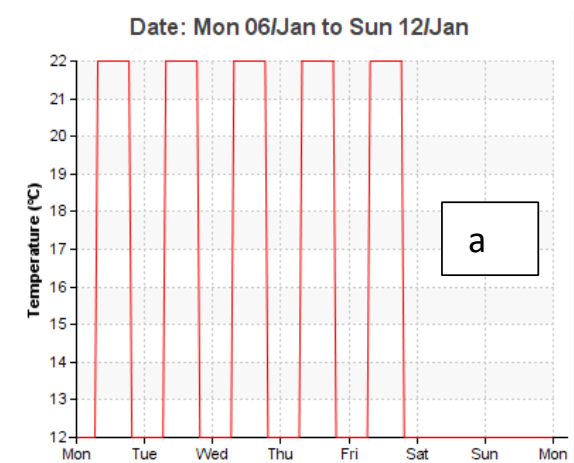

Date: Mon 06/Jan to Sun 12/Jan
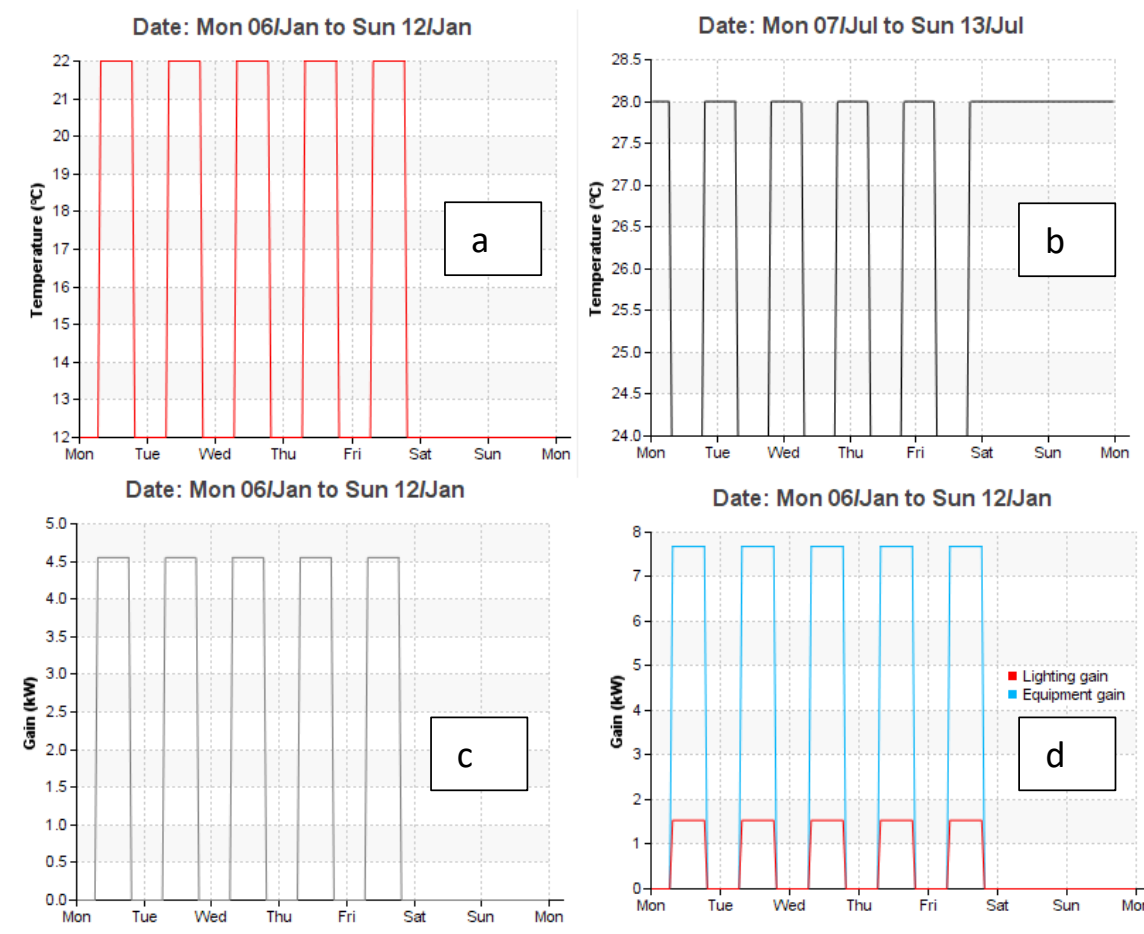

Date: Mon 06/Jan to Sun 12/Jan

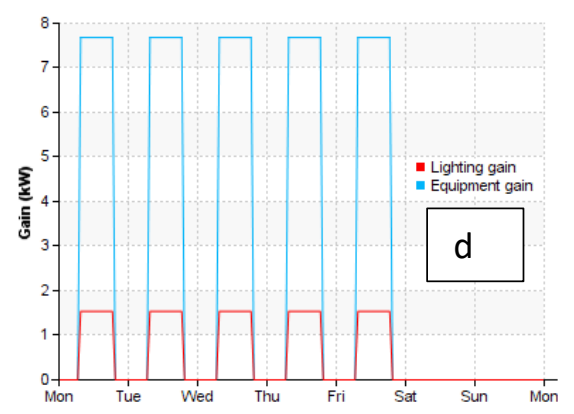

Figure 22 Profile: (a) heating season (b) cooling season (c) occupancy (d) lighting and equipment

The levels of different internal gains in the open plan office were set as follows; the density of occupancy was set to $9 \mathrm{~m}^{2}$ per person with a total heat gain of 125 Watts per person [48], the equipment heat gain was set to 15 Watts per $\mathrm{m}^{2}$ [49] and the artificial lighting heat gain was set to 12 Watts per $\mathrm{m}^{2}$ [50]. The internal heat gains weekly profiles followed that of the occupancy pattern as shown in Figure 22c and d. In order to meet the fresh air requirement, the aux ventilation was set to 10 litres per second per person [48]. Furthermore, the infiltration rate value was set to 0.3 ach as recommended in [48] for mechanically ventilated buildings built to the latest standards.

For the building energy simulation of the thermal chair, 40 units were added to each floor of the open plan office building model. The thermal chair units were equally spaced in the floor plan as shown in Figure 23. To simplify, the thermal chairs were assumed to be functioning during occupancy period i.e. turned on at 7:00 and turned off when the occupants leave the office and during the weekends. It was assumed that the chair seat and the back rest areas were incorporated with heating pads covered by the chair fabric, with each pad using up to $30 \mathrm{~W}$. It was assumed that all the thermal chairs were set to low settings during the whole simulation period. Three cases were simulated; (1) normal office chair with the zone thermostat set point kept at $22^{\circ} \mathrm{C}$ (base case), (2) normal office chair with the zone thermostat set point adjusted to $20^{\circ} \mathrm{C}$ and (3) thermal chair with the zone thermostat set point adjusted to $20^{\circ} \mathrm{C}$. The main aim of the simulations was to show how much reduction in energy demand 
can be achieved by adjusting the thermostat set point in the open plan office by $2^{\circ} \mathrm{C}$ during the heating season and what is the impact on the local thermal comfort in each chair locations. Furthermore, to determine if the thermal chair can provide adequate comfort to the users or occupants while at the same time reduce the overall energy demand of the office. Lastly, predict the contribution of the thermal chairs to the overall energy consumption of the open plan office.

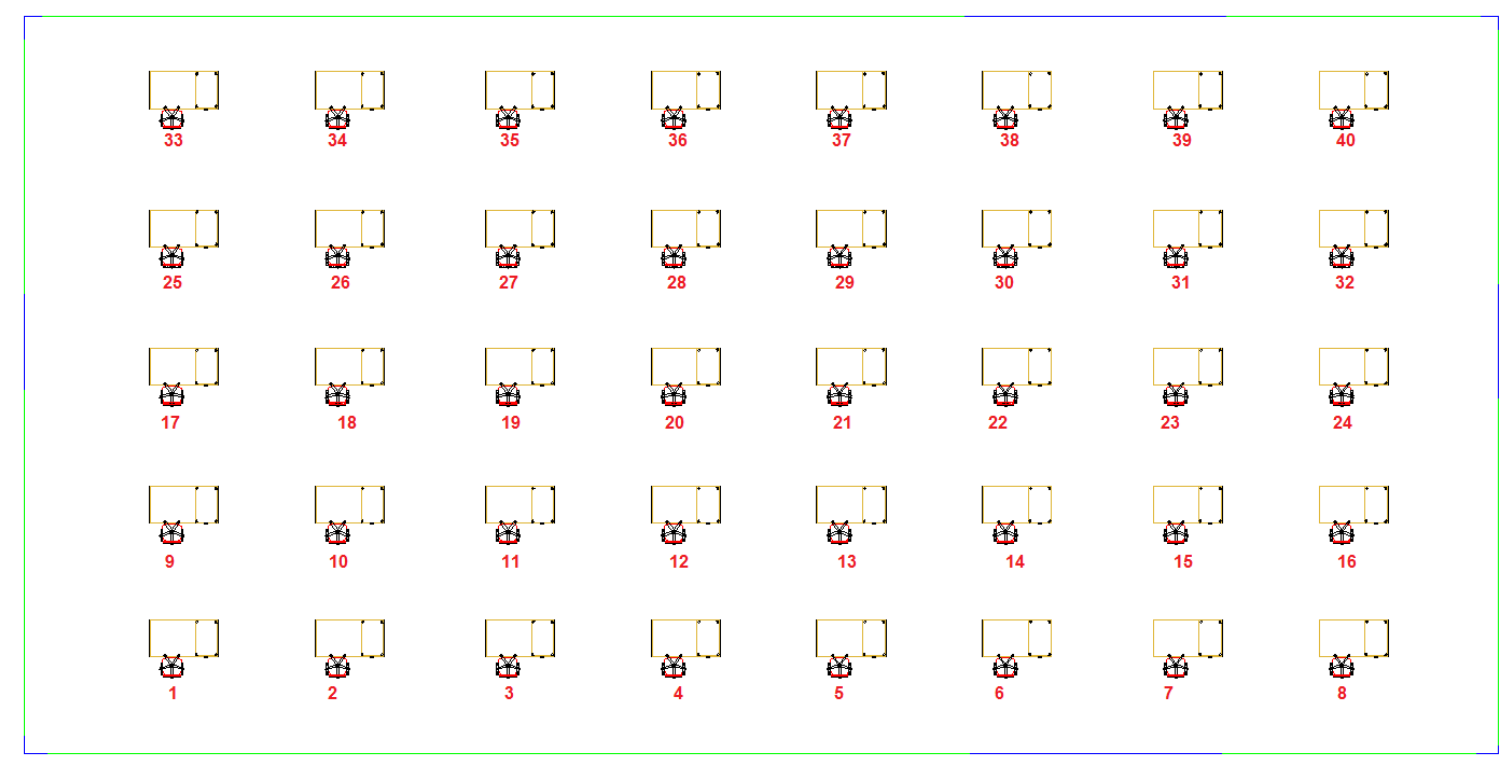

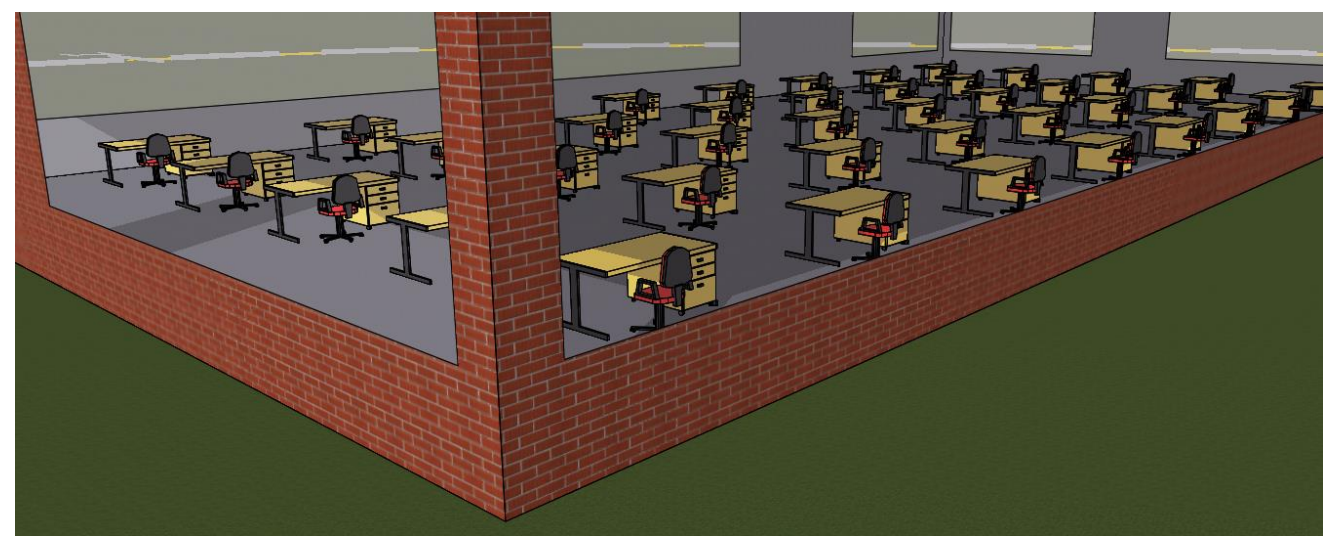

Figure 23 BES modelling of chair in the open plan office

\subsection{Field studies of thermal comfort}

Different researchers have applied both experimental chambers and field studies of thermal comfort to investigate the design and application of individual control systems. Kroner (2006) studied the impact of personalised thermal control in the daily context of an open plan office [51]. Luo et al. (2014) applied field studies of thermal comfort to compare thermal control in two office buildings in different climatic conditions [52]. This study aimed to investigate the subject in the context of every day life comparing user comfort and satisfaction before and after using the thermal chair. Therefore field 
studies of thermal comfort were applied to investigates users' views of the thermal chair in an open plan office in November in Leeds, UK. The average of the indoor dry bulb temperature was $24.1^{\circ} \mathrm{C}$ and the average of the indoor relative humidity was $29.32 \% \mathrm{RH}$. The PMV values were calculated based on ASHRAE Standard 55-2017. The equations and derivations were not included here but are fully available in [5]. Forty four occupants participated in the research by seating on the chair for the duration of an hour per person during the working hours. Participants were wearing normal indoor winter clothing. Mainly sedentary activities took place in the office and the participants were asked to go about their work as usual both before and after using the thermal chair. Their views of the thermal chair was recorded before and after the use of the chair through a survey questionnaire based on the ASHRAE seven point scale thermal sensation, comfort and satisfaction [53], as presented in Table . The mobile survey method which included multiple choice questionnaire displayed on a portable device screen allowed instant and direct individual feedback.

Table 4. Survey questions based on the ASHRAE seven-point scale [38]

\begin{tabular}{|c|c|c|c|c|c|c|c|}
\hline \multicolumn{8}{|c|}{ Currently at my desk regarding the thermal environment, I feel: } \\
\hline $\begin{array}{l}\text { Very } \\
\text { comfortable }\end{array}$ & Comfortable & $\begin{array}{l}\text { Slightly } \\
\text { comfortable }\end{array}$ & Neutral & $\begin{array}{l}\text { Slightly } \\
\text { uncomfortable }\end{array}$ & Uncomfortable & $\begin{array}{l}\text { Very } \\
\text { uncomfortable }\end{array}$ & $\begin{array}{l}\text { No strong } \\
\text { opinion }\end{array}$ \\
\hline 3 & 2 & 1 & 0 & -1 & -2 & -3 & \\
\hline \multicolumn{8}{|c|}{ Currently at my desk, the overall environment makes me feel: } \\
\hline $\begin{array}{l}\text { Very } \\
\text { satisfied }\end{array}$ & Satisfied & $\begin{array}{l}\text { Slightly } \\
\text { satisfied }\end{array}$ & Neutral & $\begin{array}{l}\text { Slightly } \\
\text { dissatisfied }\end{array}$ & Dissatisfied & Very dissatisfied & $\begin{array}{l}\text { No strong } \\
\text { opinion }\end{array}$ \\
\hline 3 & 2 & 1 & 0 & -1 & -2 & -3 & \\
\hline \multicolumn{8}{|c|}{ Currently, my overall body feels: } \\
\hline Hot & Warm & $\begin{array}{l}\text { Slightly } \\
\text { warm }\end{array}$ & Neutral & Slightly cool & Cool & Cold & $\begin{array}{l}\text { No strong } \\
\text { opinion }\end{array}$ \\
\hline 3 & 2 & 1 & 0 & -1 & -2 & -3 & \\
\hline \multicolumn{8}{|c|}{ Currently, I prefer to overall feel: } \\
\hline $\begin{array}{l}\text { Much } \\
\text { warmer }\end{array}$ & Warmer & $\begin{array}{l}\text { Slightly } \\
\text { warmer }\end{array}$ & $\begin{array}{l}\text { No } \\
\text { change }\end{array}$ & Slightly cooler & Cooler & Much cooler & $\begin{array}{l}\text { No strong } \\
\text { opinion }\end{array}$ \\
\hline 3 & 2 & 1 & 0 & -1 & -2 & -3 & \\
\hline \multicolumn{8}{|c|}{ Currently, my back feels: } \\
\hline Hot & Warm & $\begin{array}{l}\text { Slightly } \\
\text { warm }\end{array}$ & Neutral & Slightly cool & Cool & Cold & $\begin{array}{l}\text { No strong } \\
\text { opinion }\end{array}$ \\
\hline 3 & 2 & 1 & 0 & -1 & -2 & -3 & \\
\hline \multicolumn{8}{|c|}{ Currently, the seat feels: } \\
\hline Hot & Warm & $\begin{array}{l}\text { Slightly } \\
\text { warm }\end{array}$ & Neutral & Slightly cool & Cool & Cold & $\begin{array}{l}\text { No strong } \\
\text { opinion }\end{array}$ \\
\hline 3 & 2 & 1 & 0 & -1 & -2 & -3 & \\
\hline
\end{tabular}




\begin{tabular}{|l|l|l|l|l|l|l|l|}
$\begin{array}{l}\text { Very } \\
\text { satisfied }\end{array}$ & Satisfied & $\begin{array}{l}\text { Slightly } \\
\text { satisfied }\end{array}$ & Neutral & $\begin{array}{l}\text { Slightly } \\
\text { dissatisfied }\end{array}$ & Dissatisfied & Very dissatisfied & $\begin{array}{l}\text { No strong } \\
\text { opinion }\end{array}$ \\
\hline 3 & 2 & 1 & 0 & -1 & -2 & -3 & \\
\hline
\end{tabular}

The occupants included twenty nine males and fifteen females mainly aged between twenty and forty years old, and four participant aged above forty. The office was mechanically ventilated open plan office in the University of Leeds. Thermal measurements were applied at the time of the survey questionnaire to evaluate the thermal environment. Thermal measuring equipment is presented in Table .

Table 5. Velocity and thermal measuring equipment

\begin{tabular}{|c|c|c|c|c|c|}
\hline Measurement & Time & Equipment details & Resolution & Accuracy & Range \\
\hline Velocity & Instant: at workstations & Testo425 & $0.01 \mathrm{~m} / \mathrm{s}$ & $\pm 0.03 \mathrm{~m} / \mathrm{s}$ & 0 to $20 \mathrm{~m} / \mathrm{s}$ \\
\hline Dry bulb temperature & Instant: at workstations & PCE-GA 70 meter & $0.1^{\circ} \mathrm{C}$ & $\pm 0.5^{\circ} \mathrm{C}$ & 5 to $50^{\circ} \mathrm{C}$ \\
\hline Relative humidity & Instant: at workstations & PCE-GA 70 meter & $0.1^{\circ} \mathrm{C}$ & $\pm 3 \mathrm{RH}$ & 10 to $90 \% \mathrm{RH}$ \\
\hline
\end{tabular}

\section{Results and Discussion}

Figure 24 shows the results of the CFD static temperature contours of a side view cross-sectional plane inside the computational domain representing the thermal distribution around a thermal chair with a manikin. The temperature values are shown on the left side of the plot in ${ }^{\circ} \mathrm{C}$. The contour plot in the fluid domain is colour-coded and related to the colour map, ranging from 22.35 to $46.85{ }^{\circ} \mathrm{C}$. As observed in Figure 24 , the thermal chair heated the seat and back rest areas between $28-36^{\circ} \mathrm{C}$. While for the case of the standard chair with underfloor air jets, the temperature around the manikin range between $24-28^{\circ} \mathrm{C}$. For both cases, lower temperature near the face area was observed due to higher airflow movement while a higher temperature can be observed near the seat area and thigh region due to lower air movement and constrained space. From the results it was evident that depending on the position of the user (in this case a manikin), the seat and back rest regions had different temperature levels. Hence, there should be separate controls for the seat and backrest area to allow the user to have more control over the temperature distribution. This was implemented in the design of the chair used in the field tests. Measurements points are also displayed in the figure which will be later used to present the PMV results. 


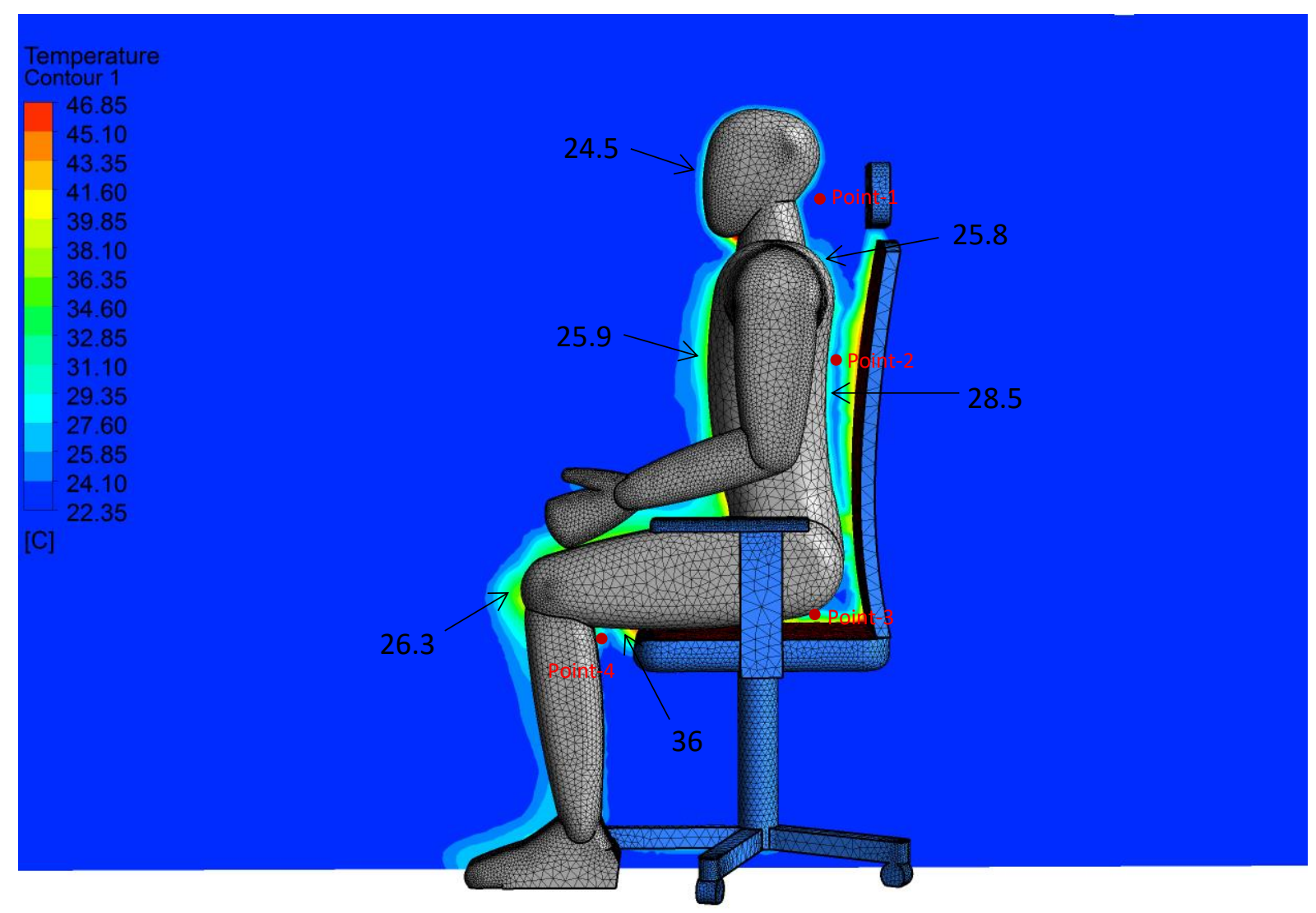

Figure 24: Cross-sectional contour showing temperature distribution around manikin with the thermal chair

Thermal comfort expresses the occupants' satisfaction with a building's thermal environment. Several models or indices have been established to predict thermal sensation and comfort and the most common of these are the Predicted Mean Vote (PMV) and Physiologically Equivalent Temperature (PET) [54]. The PMV predicts the average value of the votes of a group of occupants exposed to the similar thermal environment. It is expressed by the ASHRAE thermal sensation scale: +3 hot, +2 warm, +1 slightly warm, 0 neutral, -1 slightly cool, -2 cool and -3 cold (ASHRAE, 2013 radiant temperature, relative humidity, clothing and metabolic rate. In this study, the CFD temperature, velocity, humidity results were used to determine thermal comfort indices and assess acceptability of environmental conditions. Metabolic rate for the occupants and clothing insulation were assumed as standard values. Equations and derivations of the PMV are available in [40]. Table summarises the predicted comfort levels in the vicinity of the manikin surfaces. Based on the PMV predictions, improved comfort levels were observed for the back area and seat area. The seat area went from 0.50 (slightly cool) to 0.08 (neutral) when the chair was heated. To further optimised the design, there should be separate controls for the seat and backrest area and this was implemented in the design of the chair used in the field tests. Thermal comfort levels calculated using PMV method with set values for humidity (30\%), metabolic rate (1 met), clothing (0.7). 
Table 5: Predicted Mean Vote and thermal comfort levels in the vicinity of the manikin surfaces

\begin{tabular}{|c|c|c|c|c|}
\hline \multirow[t]{2}{*}{ Location } & \multicolumn{2}{|c|}{ With thermal chair in use } & \multicolumn{2}{|c|}{ Without thermal chair } \\
\hline & PMV & PPD (\%) & PMV & PPD (\%) \\
\hline Point -1 & -0.44 (neutral) & 9 & -0.45 (neutral) & 9 \\
\hline Point -2 & 0.17 (neutral) & 6 & -0.50 (slightly cool) & 10 \\
\hline Point -3 & 0.08 (neutral) & 5 & -0.50 (slightly cool) & 10 \\
\hline Point -4 & 0.40 (neutral) & 8 & 0.40 (neutral) & 8 \\
\hline
\end{tabular}

The benchmark building energy simulation (BES) model was initially validated with the results of [36]. Figure 25 compares the annual simulation results of the building energy demand for the open plan office, categorised into following end use categories: heating $(9.73 \%$ difference), cooling $(7.81 \%$ difference), lighting (9.11\% difference) and equipment (3.01\% difference). Overall, a good agreement was observed between the models with the average difference of $7.41 \%$. The error between the current model and [41] results for heating/cooling demand was possibly mainly due to the difference in annual schedule profile, which was not provided in the study. Another potential cause of error was the difference in tool/software used. A high annual cooling energy demand can be observed which was a result of the combination of high internal gains set for the office building and the solar gains (50\% glazing to wall ratio).

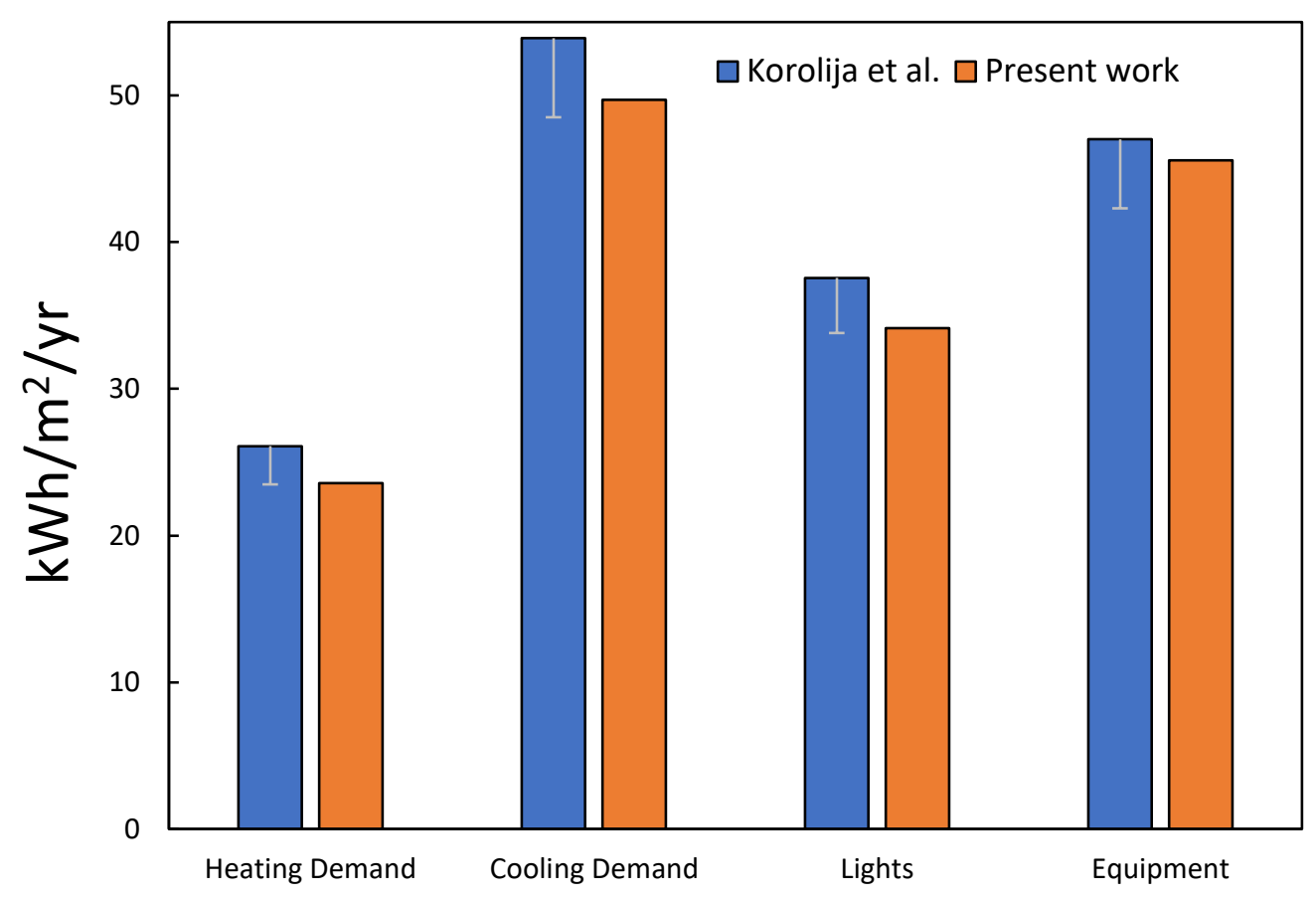

Figure 25: Comparison between the annual energy demand results of current model and of [41] 
Figure 26a presents the results of the air temperature near the different chair (normal, no heating) locations 1-8 and the outdoor dry bulb temperature from February 3 to February 9. Overall, similar air temperature values can be observed at different chair locations, with the small variation attributed to the difference in solar gains received in various locations. Overall, the temperature patterns follow the set profile with the heating switched on at 7:00 and off at 19:00 - taking time for air temperature to drop because of the stored heat is released from the fabric. During the weekend when the building was not occupied, the temperature was held at $12^{\circ} \mathrm{C}$ preventing freezing damage and mildew and mould growth. During the heating period, lowering the set point by a degree few degrees (Figure 26b - $2^{\circ} \mathrm{C}$ set point adjustment) can clearly reduce the heating energy demand, however this could also lead to discomfort to occupants as shown in Figure $26 \mathrm{c}$ which presents the results of percentage of people dissatisfied. As observed, the $2^{\circ} \mathrm{C}$ set point adjustment led to higher percentage of people dissatisfied (PPD) during occupancy hours, with a minimum of $6.52 \%$ and maximum $11.9 \%$. Figure $26 \mathrm{~d}$ compares the monthly heating energy demand (Jan 1 and Feb 28) for Floor 1 with and without setpoint adjustment. As observed, monthly heating energy demand was reduced by $27 \%$ on January and $25.4 \%$ on February.

After adjusting the thermostat set point in the open plan office by $2^{\circ} \mathrm{C}$, it was observed that significant reduction in energy demand can be achieved during the heating period however, this also led to higher thermal comfort dissatisfaction. In order to address this issue, this work proposed the use of thermal chair which can be adjusted by the occupants to the desired temperature levels. To simplify the modelling, the thermal chair heating profile was assumed to follow that of the occupancy schedule. Figure 27a compares the simulation results of the air temperature at Chair 1 for the thermal chair and normal chair (base case). As observed in Figure 27b, the thermal chair was able to reduce the PPD during the occupancy hours, with the average of 5.72\%PPD. Figure 27c compares the monthly heating energy demand for the open plan office (Ground Floor) with thermal chair and normal chair (base case). The thermal chair plot included the energy consumption of the 40 thermal chairs in Ground Floor which was $2.45 \%$ of the January heating energy demand and $2.34 \%$ of February heating energy demand. Clearly, these values will increase or decrease depending on how the occupants use each thermal chair throughout the day i.e. adjust the temperature levels depending on desired levels which also means that the predicted PPD levels will vary. Figure $27 \mathrm{~d}$ compares the hourly heating energy demand for the open plan office (Ground Floor) with thermal chair and normal chair (base case) during the month of February. A similar trend can be observed between the two plots with the heating energy demand generally peaking during the start of the occupancy period. 

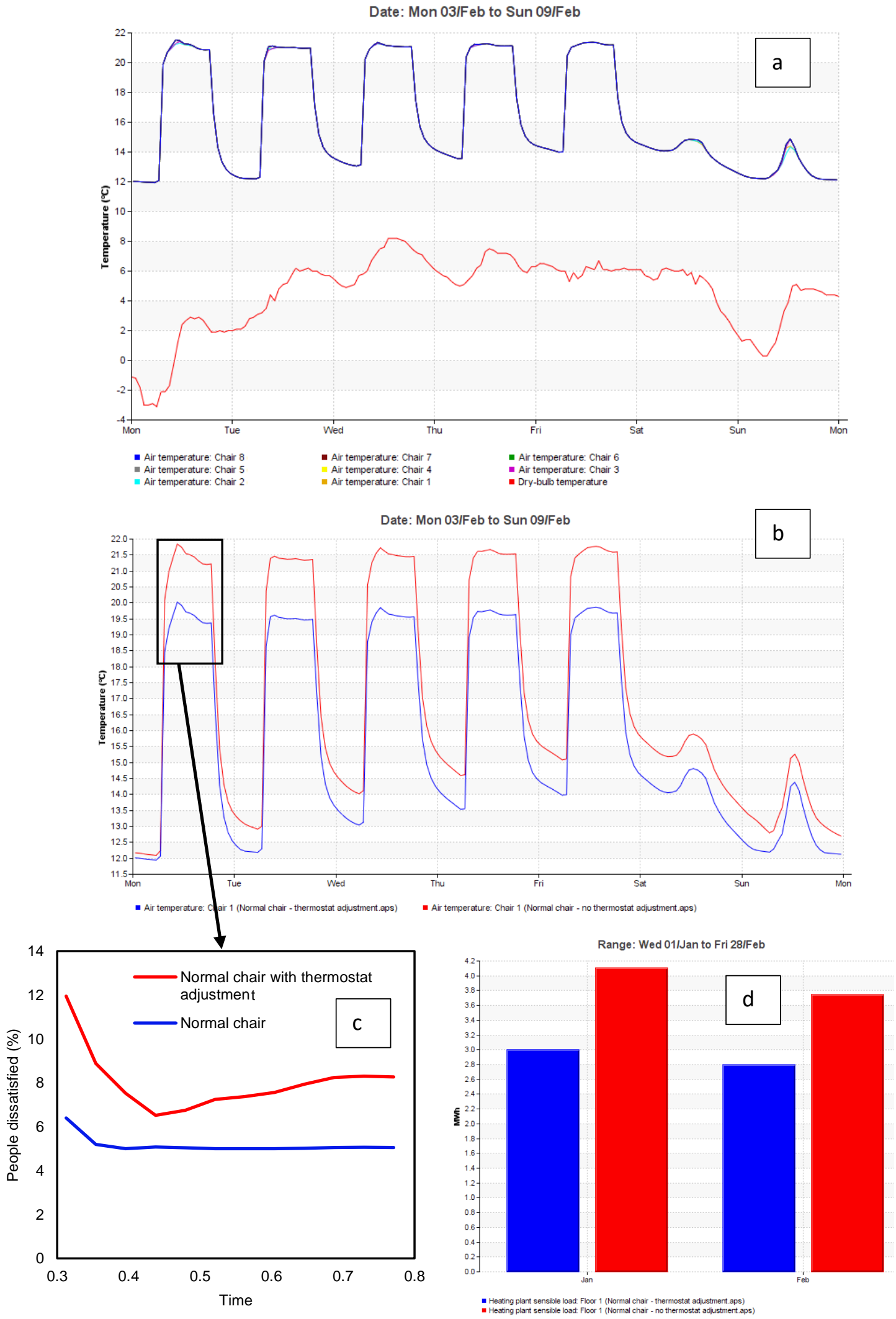

Figure 26: (a) Air temperature results in the chair 1 to 8 (no heating) and outdoor temperature; (b) comparison of air temperature in chair 1 for winter heating set point with and without adjustment; (c) effect of $2^{\circ} \mathrm{C}$ winter setpoint adjustment on the people dissatisfied (\%) during occupancy time; (d) heating load energy reduction in Floor 1 due to $2^{\circ} \mathrm{C}$ winter setpoint adjustment (Jan 1 and Feb 28) 


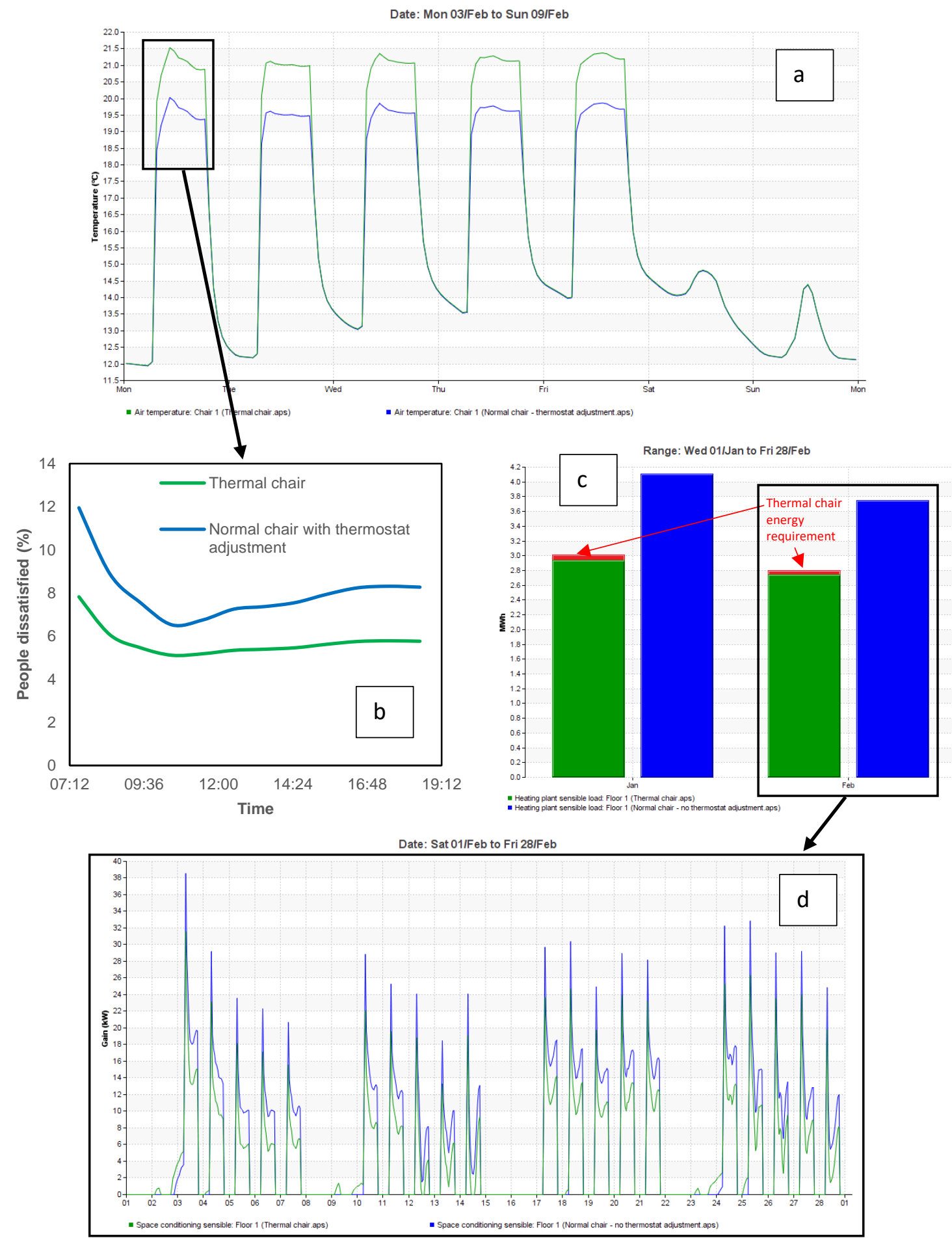

Figure 27: Comparison of (a) air temperature results (b) people dissatisfied (\%) during occupancy time (c) monthly heating energy demand for the open plan ground floor office (d) hourly heating energy demand for the base case standard chair and thermal chair

In the field studies of thermal comfort, users' views were compared before and after using the thermal chair. Figure shows the temperature settings that the respondents arranged on the seat and the back of the chair. Only two respondents did not use the temperature of the back of the chair and three 
respondents had the thermostat for the seat of the chair off. Over $86 \%$ of the occupants set the temperature settings of the seat and the back of the chair between $29^{\circ} \mathrm{C}$ and $39^{\circ} \mathrm{C}$.

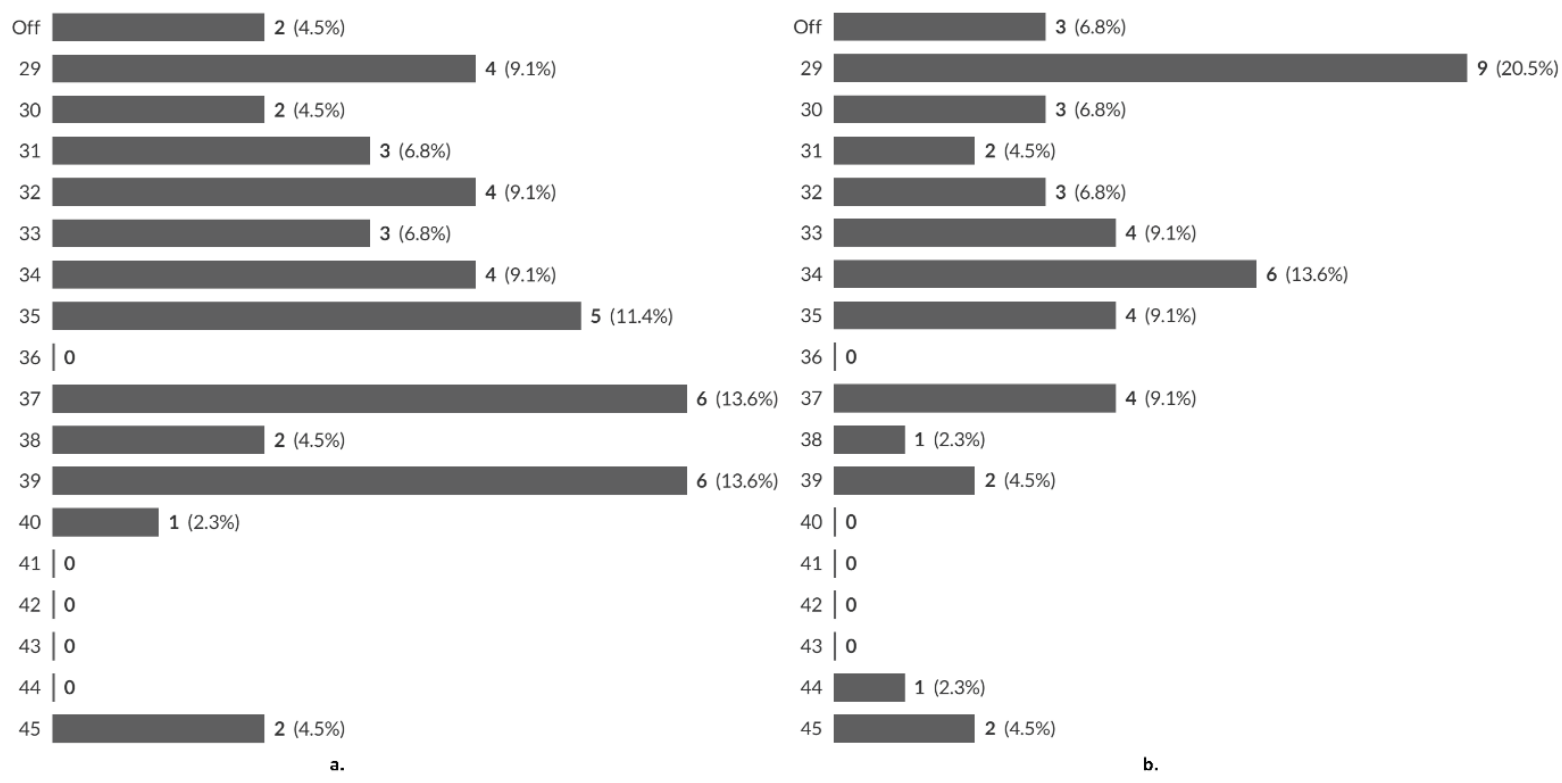

Figure 28. Temperature settings of the $a$. back and $b$. seat of the thermal chair arranged by the user

Figure demonstrates thermal sensation of the user on their back and seat before and after using the chair. $68 \%$ of the occupants had a neutral and slightly warm thermal sensation before using the thermal chair and only two respondents felt warm. The rest of the occupants (23\%) felt slight cool to cold around their back. After the use of the thermal chair, still one person felt cold, but no respondents felt cool or slightly cool around their back. $98 \%$ of the occupants felt between neutral to hot on their back, with majority feeling slightly warm to warm. Users' respondent regarding their thermal sensation of the seat of the chair followed similar pattern. $73 \%$ of the occupants felt neutral to slightly warm before using the chair, this number shifts towards the warm side after using the thermal chair, as $86 \%$ felt neutral to hot and $45 \%$ of them felt warm around the seat of the chair. These numbers are particularly interesting as it shows that users mainly had a neutral or slightly warm local thermal sensation before the use of the thermal chair. However, after being able to adjust the temperature of the seat and the back, majority of them utilised this function and reported slightly warm to warm local thermal sensations. 

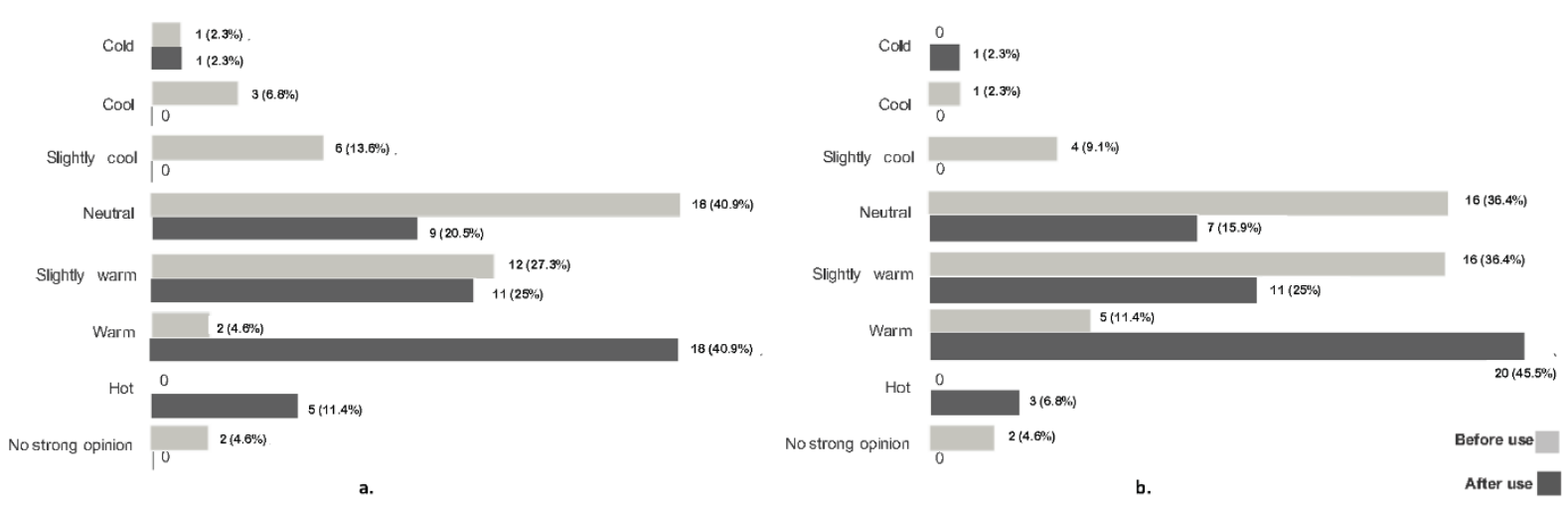

Figure 29. Thermal sensation of respondent's a. back and b. seat reported by the respondent before and after using the thermal chair

Respondents reported much higher comfort levels after using the thermal chair, as presented in Figure . The number of "comfortable" and "very comfortable" users increased from $57 \%$ to $77 \%$. The bar chart shows slightly warm or neutral thermal sensation before the experiment, while after using the chair majority of the users reported slightly warm or warm overall thermal sensations.
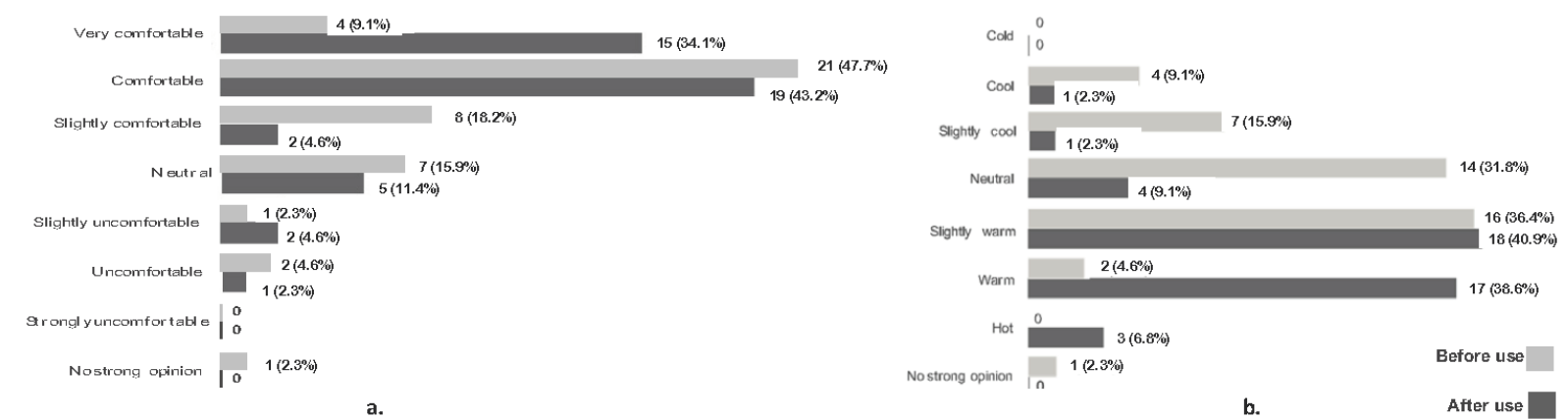

Figure 30. a. Users' views of their comfort and b. thermal sensation before and after using the thermal chair

The number of occupants feeling a neutral thermal sensation dropped from $32 \%$ to only $9 \%$, while their comfort level and satisfaction increased. Their satisfaction increased from $45 \%$ to $80 \%$, as illustrated in Figure. Majority of the occupants set the temperature of both the seat and the back between 29 to $35^{\circ} \mathrm{C} .43 \%$ reported to desire no change in the temperature and $39 \%$ preferred slightly warmer temperature. This suggested that occupants preferred to feel slightly warm to warm. $82 \%$ of the occupants expressed their satisfaction level as "satisfied" or "very satisfied" regarding the performance of the thermal chair, as demonstrated in Figure . 


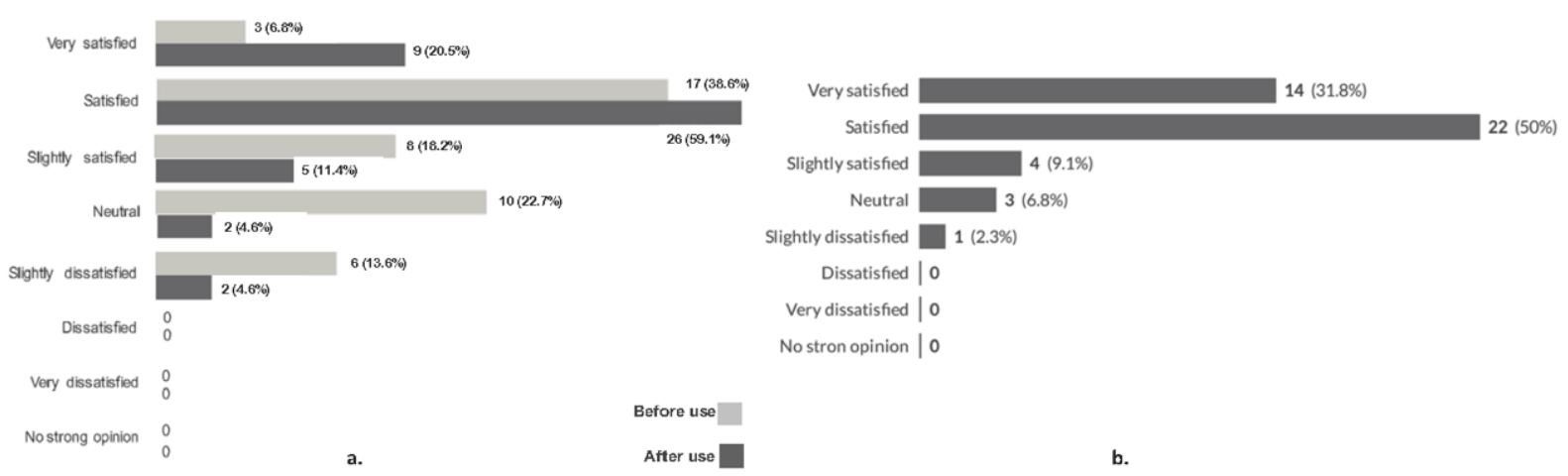

Figure 31. a. Users' overall satisfaction with the thermal environment and b. their satisfaction using the thermal chair

One of the questions focused on users' preference in having separate thermostats for the back and the seat of the chair. $86 \%$ of the respondents preferred separate controls and $14 \%$ liked an individual thermostat for the whole chair.

\section{Conclusion and Future Work}

The aim of this work was to improve user comfort and satisfaction regarding the thermal environment in the open plan office, which is a current challenge in the workplace and limited research addresses it. The work utilised Computational Fluid Dynamic (CFD), Building Energy Simulation (BES) and field testing to assess thermal comfort and energy performance of a thermal chair which allows users to control heating that is provided directly through the surfaces of seat and backrest. The numerical CFD analysis predicted an improvement in local thermal comfort. Thermal sensation of the occupant was expected to change from slightly cool to neutral around the back, and from neutral to slightly warm around the seat. This result was to a degree in agreement with the results of the field studies, as there was a move from slightly cool and mainly neutral to slightly warm and warm after the use of the chair. Also, similar move from neutral and slightly warm towards warm was reported by the respondents after using the thermal chair. Although the results of both numerical CFD and field studies indicated a move towards warmer thermal sensations, the numerical CFD analysis showed a small move, while respondents reported much bigger move. The numerical analysis predicted the user's thermal comfort for the seat and backrest region as -0.50 slightly cool before and $0.08-0.17$ neutral thermal sensations after the use of the thermal chair. The field study analysis based on the occupants' responses indicated much higher comfort and satisfaction levels after using the thermal chair. The overall comfort level was improved by $20 \%$ and the overall satisfaction with the thermal environment was increased by $35 \%$ after using the thermal chair. $82 \%$ of the occupants expressed their satisfaction level as satisfied or very satisfied regarding the performance of the thermal chair. 
The results emphasised the importance of the application of detailed numerical analysis to carry out a detailed analysis of the thermal distribution around the thermal chair providing opportunities for optimisation. From the CFD results it was evident that depending on the position of the user (in this case a manikin), the seat and back rest regions had different temperature levels. Hence, there should be separate controls for the seat and backrest area to allow the user to have more control over the temperature distribution. The CFD results showed that thermal comfort levels near the seat and back rest area were improved however it also showed that areas such as the face and legs regions cannot be improved by the current design therefore further work is necessary to redistribute the heat to other areas of the user. The results of the field studies also suggested separate thermal controls, as $86 \%$ of the respondents agreed with "do you prefer to have separate controls for back and seat?" and they mainly wanted to set the temperatures between $29^{\circ} \mathrm{C}$ and $39^{\circ}$. In addition, comparing the temperature settings on the chair and the status of thermal sensation before and after using the chair suggests that occupants preferred thermal conditions warmer than neutral for their overall thermal sensation, the thermal sensation on their back and their seat. This suggested that occupants preferred to feel slightly warm or warm and not necessarily neutral in order to feel comfortable.

The thermal chair energy consumption was relatively low $(0.03 \mathrm{~kW})$ when compared with that of personal heaters, which are about $1-1.5 \mathrm{~kW}$. It is worth noting that although personal heaters are inefficient, it was used by some users in the case study office building for added warmth (supplementary heating) during the winter period. Thermal chairs have a good potential for energy savings in buildings particularly during cold winter where the device could be used. Building Energy simulation (BES) of a three-story open plan office building with thermal chairs was also carried out to determine if the thermal chair can provide adequate comfort to the users or occupants while at the same time reduce the overall energy demand of the office. The benchmark model was validated using previous work's data and good agreement was observed. After adjusting the thermostat set point in the open plan office by $2^{\circ} \mathrm{C}$, it was observed that significant reduction in energy demand can be achieved during the heating period. Monthly heating energy demand was reduced by $27 \%$ on January and $25.4 \%$ on February. However, this also led to higher thermal comfort dissatisfaction. To address this, thermal chairs were incorporated in to the open plan office. The results showed that the thermal chair was able to reduce the PPD during the occupancy hours. The thermal chair's contribution to the overall heating energy requirement was minimal, the energy consumption of the 40 thermal chairs in Ground Floor was $2.45 \%$ of the January heating energy demand and $2.34 \%$ of February heating energy demand. The results showed that the thermal chair could be used to enable wider range of indoor ambient temperatures, maintain the comfort level and at the same time use sufficiently low energy. 
This study recommends the further investigation of the thermal chair performance during different periods of the day and year. This study also recommends improvement in the CFD modelling and analysis particularly in regard to the modelling of the manikin models. Furthermore, thermal sensations other than neutral are required to be considered in thermal comfort research, CFD, BES and field studies of thermal comfort. Other aspects of system, i.e. capital cost, operation cost, control system, human behaviour should be investigated before the system is put to commercial application. In addition, the advantages of personalised comfort on improving workplace productivity and reducing the sick building syndrome are worth investigating. Finally, the design of the chair requires improvement to include heating for other body parts as well as sensors for energy efficiency.

\section{Acknowledgements}

The authors gratefully acknowledge the contribution of the occupants of the case study building.

\section{References}

1. OECD/IEA. 2014. http://www.iea.org/topics/sustainablebuildings/.

2. Pérez-Lombard, L., Ortiz, J., Pout, C., 2008. A review on buildings energy consumption information. Energy and Buildings, 40, pp. 394-398,

3. Cabon Trust. 2017. Heating, ventilation and air conditioning overview guide https://www.carbontrust.com/resources/guides/energy-efficiency/heating-ventilation-and-air-conditioninghvac/

4. IEA Technology roadmap. 2013. Energy-efficient buildings: heating and cooling equipment.

5. ASHRAE, ASHRAE Standard 55-2010: Thermal Environmental Conditions for Human Occupancy. Atlanta: American Society of Heating, Refrigerating and Air-Conditioning Engineers, 2010.

6. Shahzad S. 2014. Individual Thermal Control in the Workplace. University of Edinburgh.

7. Shahzad, S., Brennan, J., Theodossopoulos, D., Hughes, B., Calautit, J.K. 2017. Energy and comfort in contemporary open plan and traditional personal offices. Applied Energy, 185, pp.1542-1555.

8. Roaf, S., Horsley, A., Gupa, R. 2004. Closing the loop; Benchmarks for sustainable buildings, London, RIBA Enterprises Ltd.

9. Rollins, V., Swift, G.H. 1997. Psychological issues: a multifaceted problem, a multidimensional approach. In: ROSTRON, J. (ed.) Sick Building Syndrome; Concepts, issues and practice. London: E \& FN Spon.

10. Arens, E., Humphreys, M. A., de Dear, R. \& Zhang, H. 2010. Are 'Class A' Temperatue Requirements Realistic or Desirable? Building and Environment, 45, pp. 4-10.

11. Kroner, W. M. 2006. Employee Productivity and the Intelligent Workplace. In: Clements-Croome, D. (ed.) Creating the Productive Workplace. London: Taylor \& Francis.

12. Melikov, A. 2004. Personilised Ventilation. Indoor Air, 14, pp. 157-167.

13. Melikov, A., Pitchurov, G., Naydenov, K., Langkilde, G. 2005. Field study of occupant comfort and the office thermal environment in rooms with displacement ventilation. Indoor Air, 15, pp. 205-214.

14. Zhang, H., Arens, E., Zhai, Y. 2015. A review of the corrective power of personal comfort systems in non-neutral ambient environments. Building and Environment, 91, pp. 15-41.

15. Mower, D. 1976. Perceived intensity of peripheral thermal stimuli is independent of internal body temperature. Journal of Comparative and Physiological Psychology, 90, pp. 1152-1155.

16. Attia, M., 1984. Thermal Pleasantness and Temperature Regulation in Man. Neuroscience \& Biobehavioral Reviews, 8(3), pp. 335-342.

17. Zhang, H. 2003. Human thermal sensation and comfort in transient and non-uniform thermal environment, Ph. D. Thesis, CEDR, University of California at Berkeley, pp. 415.

18. Arens, E, Zhang H, Huizenga C. 2006. Partial- and whole body thermal sensation and comfort, Part I: uniform environmental conditions. Journal of Thermal Biology, 31, pp. 53- 59. 
19. Luo, M., Cao, B., Ji, W., Ouyang, Q., Lin, B. and Zhu, Y. 2016. The underlying linkage between personal control and thermal comfort: Psychological or physical effects?. Energy and Buildings, 111, pp.56-63

20. Halvoňová, B.., Melikov A., K., 2010. Performance of “ductless" personalized ventilation in conjunction with displacement ventilation: Impact of intake height, Building and Environment, 45, 4, pp. 996-1005.

21. Melikov, A., K., Radim Cermak, Milan Majer. 2002. Personalized ventilation: evaluation of different air terminal devices, Energy and Buildings, 34, pp. 829-836.

22. Watanabe, S., Melikov, A, K., Knudsen, G., L. 2009. Design of an individually controlled system for an optimal thermal microenvironment, Building and Environment, 45, pp. 549-558.

23. Conceicao, E., Z, E., Lucio M., J., R., Rosa S., P., Custodio A.,L.,V., Andrade, R., L., Meira M., J., P., A. 2010. Evaluation of comfort level in desks equipped with two personalized ventilation systems in slightly warm environments, Building and Environment, 45, pp. 601-609

24. Mao, N., Pan, D., Li, Z., Xu, Y., Song, M., Deng, S. 2017. A numerical study on influences of building envelope heat gain on operating performances of a bed-based task/ambient air conditioning (TAC) system in energy saving and thermal comfort. Applied Energy, 192, pp. 213-221.

25. Tsuzuki, K., Arens, E., Bauman, F., Wyon, D. 1999. Individual thermal comfort control with desk-mounted and floor-mounted task/ambient conditioning (TAC) systems, Center for the Built Environment UC Berkeley.

26. Amai, H., Tanabe, S. I., Akimoto, T., Genma, T. 2007. Thermal sensation and comfort with different task conditioning systems. Building and Environment, 42(12), pp.3955-3964.

27. Niu, Gao, N., Phoebe, M., Huigang, Z., 2007. Experimental study on a chair-based personalized ventilation system, Building and Environment, 42(2), pp. 913-925.

28. Watanabe, S., Shimomura, T., Miyazaki, H. 2009. Thermal evaluation of a chair with fans as an individually controlled system. Building and Environment, 44, pp. 1392-1398

29. Sun,W., Cheong, K., W., D., Melikov, A., K,. 2012. Subjective study of thermal acceptability of novel enhanced displacement ventilation system and implication of occupants' personal control, Building and Environment, Volume 57, pp. 49-57.

30. Pasut., W., Zhang H., Arens E., Zhai, Y. 2014. Energy-efficient comfort with a heated/cooled chair: Results from human subject tests, Building and Environment, 84, 2014, pp. 10-21.

31. Pasut, W., Zhang, H., Kaam, S., Arens E., Zhai, Y. 2013. Effect of a heated and cooled office chair on thermal comfort, Center for the Built Environment UC Berkeley.

32. Hyperchair. Persconal comfort systems; http://www.personalcomfortsystems.com/

33. Kogawa, Y., Tatsuo, N., Onga, A. 2007. Practical Investigation of Cool Chair in Warm Offices, Proceedings of Clima 2007 WellBeing Indoors.

34. Onga, A., Nobe., T., Kogawa, Y. 2007. Time Series Analysis of Cool Chair Operating Conditions, Proceedings of Clima 2007 Well Being Indoors.

35. Hughes, B.R., Calautit, J.K., Sa Ghani, S.A. 2012. The development of commercial wind towers for natural ventilation: A review. Applied Energy, 92, pp. 606-627.

36. Sofotasiou, P., Calautit, J.K., Hughes, B.R. O'Connor, D. 2016. Towards an integrated computational method to determine internal spaces for optimum environmental conditions. Computers \& Fluids, 127, pp. 146-160.

37. Calautit, J.K., O'Connor, D., Sofotasiou, P., Hughes, B.R. 2015. CFD Simulation and Optimisation of a Low Energy Ventilation and Cooling System. Computation, 3, pp. 128-149.

38. Calautit, J.K., Hughes, B.R., 2014. Wind tunnel and CFD study of the natural ventilation performance of a commercial multi-directional wind tower. Building and Environment, 80, pp.71-83.

39. Calautit, J., K., Hughes, B., R., Shahzad, S. 2015. CFD and wind tunnel study of the performance of a unidirectional wind catcher with heat transfer devices. Renewable Energy, pp. 83, 85-99.

40. Hosseini, S.H., Shokry, E., Ahmadian Hosseini, A.J., Ahmadi, G., Calautit J.K. 2016. Evaluation of airflow and thermal comfort in buildings ventilated with wind catchers: Simulation of conditions in Yazd City, Iran. Energy for Sustainable Development, 35, pp.7-24.

41. Nasir, D.S.N.M., Hughes, B.R., Calautit, J.K. 2017. A CFD analysis of several design parameters of a road pavement solar collector (RPSC) for urban application. Applied Energy, 186, pp. 436-449.

42. Nejat, P., Calautit, J.K., Majid, M.Z.. Hughes, B.R., Jomehzadeh, F. 2016. Anti-short-circuit device: A new solution for short-circuiting in windcatcher and improvement of natural ventilation performance. Building and Environment, 105, pp. 24-39.

43. Yan, Y., Li, X., Yang, L., Tu, J. 2016. Evaluation of manikin simplification methods for CFD simulations in occupied indoor environments. Energy and Buildings, 127, pp. 611-626

44. Yan, Y., Li, X., Tu, J. 2016. Effects of manikin model simplification on CFD predictions of thermal flow field around human bodies, Indoor and Built Environment, 27, pp. 1185-1197. 
45. Korolija, I., Marjanovic-Halburd, L., Zhang, Y., Hanby, V., I. 2011. Influence of building parameters and HVAC systems coupling on building energy performance. Energy and Buildings, 43, 6, pp. 1247-1253

46. ODPM, The Building Regulations - Approved Document L2A: Conservation of fuel and power (New buildings other than dwellings) (2006 edition), in: Office of the Deputy Prime Minister, London, UK, 2006.

47. ASHRAE Handbook 2007: HVAC Applications, American Society of Heating, Refrigerating and Air-Conditioning Engineers, Inc., Atlanta, GA (2007)

48. CIBSE Guide A: Environmental Design Chartered Institution of Building Services Engineers, London, UK (2006)

49. CIBSE Guide B: Heating, Ventilating, Air Conditioning and Refrigeration Chartered Institution of Building Services Engineers, London, UK (2005)

50. ECG019, Energy Efficiency-Best Practice Programme-Energy Consumption Guide 019: Energy Use in Offices, in: Carbon Trust, 2003.

51. Kroner, W. M. 2006. Employee Productivity and the Intelligent Workplace. In: Clements-Croome, D. (ed.) Creating the Productive Workplace. London: Taylor \& Francis.

52. Luo, M., Cao, B., Zhou, X., Li, M., Zhang, J., Ouyang, Q. and Zhu, Y., 2014. Can personal control influence human thermal comfort? A field study in residential buildings in China in winter. Energy and Buildings, 72, pp.411-418.

53. ASHRAE 2009. ASHRAE Handbook: Fundamentals. SI Edition ed. Atlanta: American Society of Heating, Refrigerating and Air-Conditioning Engineers, Inc.

54. ISO, ISO 7730: 2005. Ergonomics of the thermal environment - analytical determination and interpretation of thermal comfort using calculation of the PMV and PPD indices and local thermal comfort criteria 